\title{
Associação entre fatores da dieta e tumores de cérebro em adultos: uma revisão da literatura
}

\author{
Association between dietary factors \\ and brain tumors in adults: a review
}

Rosângela Alves Pereira 1

Sérgi o Koifman 2

\footnotetext{
1 Instituto de Nutrição Josué de Castro, Universidade Federal do Rio de Janeiro. Centro de Ciências da Saúde, Bloco J, 20 andar, Il ha do Fundão, Rio de Janeiro, RJ 21941-590, Brasil. rpereira@nitnet.com.br 2 Departamento de Epidemiologia e Métodos Quantitativos em Saúde, Escola Nacional de Saúde Pública, Fundação Oswaldo Cruz. Rua Leopoldo Bulhões 1480 , Rio de Janeiro, RJ 21041-210, Brasil.
}

Abstract This paper reviews the scientific literature published from 1986 to 1999 assessing the relationship between di etary factors and brain tumors in adults. The work aimed to describe the estimated associations and to discuss methodological aspects that might influence the results. The studies generally appear to show a moderate association between dietary factors and brain tumors. There is evidence that N-nitroso compounds enhance the risk of developing such tumors and that consumption of fruits and vegetables can inhibit them. Use of proxies in most of the studies may have introduced bias, thereby contributing to some inconsistent observations. Epidemiological research on di et and brain tumors should consider other components of food besi des $\mathrm{N}$-nitroso compounds. It is important to carefully assess exposure periods and to prevent bias related to control selection and recall.

Key words Diet; Brain Neoplasms; Neoplasms

Resumo Desenvolveu-se uma revisão da literatura científica publicada entre 1986 e 1999, sobre a associ ação entre fatores da dieta e os tumores de cérebro em adultos, com o obj eti vo de descrever as associações observadas e di scutir os aspectos metodológi cos que possam influenciar os resultados observados. De um modo geral, os estu dos revi sados parecem apontar na direção de uma associação moderada entre os fatores da dieta e os tumores de cérebro; há evidências de que o consumo de compostos $\mathrm{N}$-nitroso possa favorecer o desenvolvimento desses tumores, e de que o consumo de vegetais e frutas pode ter papel na sua ini bição. A partici pação dos respondentes substitutos nos estudos anali sados, pode ter introduzi do viés de memória nas informações levantadas e contribuído para a inconsistência dos achados. As investi gações epi demi ológi cas sobre a associ ação da di eta com estes tumores devem consi derar a análise de ou tros fatores alimentares, além dos compostos $\mathrm{N}$-nitroso. É necessári o preci sar os períodos de exposi ção que devem ser investigados e contar com criteriosa metodologia, de modo a prevenir a ocorrência de tendenci osidades relaci onadas com a sel eção dos controles e minimizar os efeitos do vi és de memória.

Palavras-chave Dieta; Neoplasias Cerebrais; Neoplasias 


\section{Introdução}

Embora sejam percebidos como doença rara, os tumores de cérebro vêm ganhando importância no cenário da epidemiologia do câncer devido ao aparente aumento da sua incidência e por sua alta letalidade.

Mais de $90 \%$ dos tumores que atingem o sistema nervoso ocorrem no cérebro ou nas suas proximidades. Raramente são observados tumores nas células nervosas propriamente ditas; os tumores de cérebro desenvolvem-se, principalmente, nas células da glia, que formam a estrutura de sustentação das células nervosas. Entre os adultos, os tumores intracranianos mais freqüentes são gliomas, meningiomas e neuromas. Os gliomas são classificados em sub-tipos, de acordo com a semelhança histológica entre as células tumorais e as células gliais, e podem ser: astrocitomas, glioblastomas (tumores astrocíticos), oligodendrogliomas e ependimomas. Os meningiomas desenvolvem-se nas meninges e os neuromas nas bainhas de mielina dos nervos cranianos sendo, em geral, benignos; contudo mesmo benignos e de lento crescimento, produzem sérias alterações neurológicas e representam risco de vida (Inskip et al., 1995; Preston-Martin \& Mack, 1996; Thomas \& Inskip, s.d.).

Nos Estados Unidos, a taxa de incidência de tumores do sistema nervoso central tem aumentado cerca de $1,2 \%$ ao ano desde 1973 e a taxa de mortalidade $0,7 \%$. Para o grupo de pessoas com menos de 65 anos de idade estas taxas têm aumentado 0,7\% e 0,5\% ao ano, respectivamente (Inskip et al., 1995). As taxas de incidência ajustadas para esse país entre 1983 e 1987 , foram de 10,4 e 6,7 por 100.000 para homens e mulheres entre 35 e 64 anos de idade (Preston-Martin \& Mack, 1996).

No Brasil, os dados indicam que houve um incremento nas taxas de mortalidade específicas para tumor de cérebro, particularmente entre a população com mais de cinqüenta anos de idade. Entre 1980 e 1995, as taxas de mortalidade para indivíduos entre 50 e 59 anos de idade passaram de 4,5 para 7,3 por 100.000 habitantes, representando uma elevação de $62,0 \%$. Entre os indivíduos com idades entre 60 e 69 anos o incremento foi da ordem de $84,4 \%$, passando de 6,4 para 11,8 por 100.000 habitantes, no período considerado (DATASUS, 1998). Possivelmente, nesses incrementos estão embutidos, além da melhor capacidade de diagnóstico das neoplasias de cérebro, os reflexos do processo de urbanização da população brasileira e as modificações no acesso aos serviços de assistência à saúde.
A comparação das taxas de câncer de cérebro entre diferentes países e a interpretação das suas variações das taxas ao longo do tempo é incerta devido às inconsistências nos métodos de registro, à disponibilidade de recursos para o diagnóstico eàs mudanças que foram feitas no Código Internacional de Doenças nos últimos quarenta anos. $\mathrm{O}$ avanço representado pela introdução de procedimentos diagnósticos mais precisos e menos invasivos, como a tomografia computadorizada e a ressonância magnética, tem sido apontado como um dos fatores que explicam o incremento nas taxas desses tumores nas últimas décadas. Entretanto, a magnitude e a constância com que se elevam os coeficientes, dificilmente comportariam apenas esta explicação (Gold, 1982; Koifman, 1995).

Ainda se conhece relativamente pouco sobre os possíveis agentes causais associados com esses tumores. Diversos fatores de risco para neoplasias de cérebro têm sido investigados em estudos epidemiológicos, contudo, até o momento, não existem evidências suficientes para caracterizar aqueles causalmente associados a esse tipo de tumor, com exceção da radiação ionizante em altas doses (Inskip et al., 1995).

O processo de carcinogênese pode ser afetado por fatores nutricionais (como a obesidade) e alimentares (como os nutrientes, os contaminantes e os aditivos encontrados nos al imentos) por meio de mecanismos que favoreçam ou inibam o seu desenvolvimento. Os alimentos podem conter substâncias carcinogênicas, mas também estão presentes outras substâncias que atuam na redução dos danos ao material genético da célula causados por agentes mutagênicos ambientais. Assim, a associação entre dieta e câncer é complexa, e os processos que envolvem a relação entre a dieta e o aparecimento de neoplasias freqüentemente não ficam totalmente esclarecidos (Kohlmeier et al., 1995; World Cancer Research Fund/ American Institute for Cancer Research, 1997).

A investigação epidemiológica sobre a associação entre dieta e câncer é permeada por uma série de dificuldades metodológicas. A primeira é relativa aos métodos de avaliação do consumo dietético, pois ainda não foram desenvolvidos instrumentos que forneçam informação acurada dos níveis de exposição ao Iongo do tempo. Embora a utilização de biomarcadores contribua para a estimação mais precisa dos níveis de nutrientes no organismo, esta não elimina o uso de instrumentos adequados para a estimação do consumo de alimentos, especialmente o consumo pregresso. Uma outra dificuldades diz respeito ao período de indução do câncer e à necessidade de deter- 
minar adequadamente o momento em que o consumo de alimentos deve ser mensurado. Por fim, outro problema é colocado pela grande variedade de substâncias ativas nos alimentos e seus diferenciados mecanismos de atuação e de interação entre si e com outros fatores endógenos e exógenos (Kohlmeier et al., 1995). Tais limitações geram problemas como o erro de medida, classificação inadequada dos indivíduos estudados, colinearidade entre as variáveis observadas e a obtenção de associações pouco consistentes.

As hipóteses a respeito da associação entre fatores da dieta e tumores de cérebro relacionam-se, sobretudo, aos compostos $\mathrm{N}$-nitroso como favorecedores do desenvolvimento desses tumores. Tem sido avaliado, também, o papel de antioxidantes como as vitaminas $\mathrm{C} \mathrm{e} \mathrm{E}$ atuando como protetores, particularmente, na inibição da nitrosação dos precursores dos compostos N-nitroso (Preston-Martin \& Mack, 1996).

Os compostos $\mathrm{N}$-nitroso constituem uma categoria de substâncias que contêm nitrosaminas e nitrosamidas, produzidas através da reação de nitrosação entre nitritos e aminas e amidas. Estes compostos têm se revelado neurocarcinógenos potentes em experimentos com animais. Por outro lado, existem fortes evidências da participação dos compostos $\mathrm{N}$-nitroso no aparecimento do câncer de estômago, esôfago, cólon, nasofaringe e bexiga (Inskip et al., 1995; Mirvish, 1995).

A exposição aos compostos $\mathrm{N}$-nitroso pode ocorrer por via endógena ou exógena. A exposição endógena, que representa cerca de $50 \%$ das exposições aos compostos N-nitroso, é produto da nitrosação de seus precursores nitritos e nitratos, que ocorre, principalmente, no estômago, onde o ácido gástrico age como catalisador. O potencial carcinogênico destas substâncias está relacionado com a capacidade que têm de formar adutos pro-mutagênicos no DNA celular (Miller \& Miller, 1986; Mirvish, 1986; Preussman, 1984; Shephard et al., 1987).

A exposição exógena às nitrosamidas é pouco comum porque a maioria destes compostos é instável na presença de $\mathrm{pH}$ neutro ou alcalino e, portanto, não se mantêm em alimentos ou no ambiente. Por outro lado, as nitrosaminas são mais freqüentemente encontradas em alimentos, pesticidas, tabaco, bebidas alcóolicas, medicamentos, cosméticos e no manuseio de máquinas industriais. Enquanto as nitrosamidas decompõem-se em formas biologicamente ativas através de reação não-enzimática no $\mathrm{pH}$ fisiológico, as nitrosaminas requerem a mediação de enzimas na ativação para a forma carcinogênica. Porém, as evidências experimentais da relação entre as nitrosaminas e os tumores de cérebro são mais fracas do que as que tratam das nitrosamidas (Choi, 1985; Duarte \& Mídio, 1996; Inskip et al., 1995; Miller et al., 1984; Mirvish, 1986; Preussman, 1984; Sen, 1986).

Os al imentos que contêm maiores quantidades de compostos $\mathrm{N}$-nitroso são a cerveja, as carnes e os peixes em conserva ou defumados, os queijos, os pescados processados ou cozidos e o toucinho defumado frito (bacon) (Choi, 1985; Eichholzer \& Gutzwiller, 1998; Miller \& Miller, 1986; Miller et al., 1984; Shephard, et al., 1987). Altos níveis de nitritos estão presentes nas carnes conservadas, no peixe, nos cereais e no leite e derivados. A principal fonte de nitratos na dieta são os vegetais e em segundo plano, a água, cuja contaminação é proveniente das atividades agrícolas e industriais. Grandes concentrações de nitratos nos vegetais são, usualmente, conseqüência do uso excessivo de fertilizantes à base de nitrogênio (Duarte \& Mídio, 1996; Preussman, 1984).

Os compostos N-nitroso têm sido associados ao desenvolvimento de câncer, especialmente, de tumores localizados na cavidade oral, no trato respiratório, no sistema digestivo, na bexiga e no cérebro. Embora a carcinogenicidade desses compostos tenha sido evidenciada em experimentos com animais, estabelecer a sua relação causal com o câncer em humanos não é tão simples, porque em estudos observacionais as exposições são altamente complexas, havendo a ocorrência simultânea de diversos fatores que podem promover ou inibir a sua formação (Eichholzer \& Gutzwiller, 1998; Howe et al., 1986; Mirvish, 1995; Preston-Martin \& Correa, 1989).

O efeito adverso das nitrosaminas e nitritos tem sido demonstrado em investigações abordando o risco de câncer em crianças - inclusive o câncer de cérebro. Esse efeito foi particularmente importante quando foram observados consumos elevados de carnes em conserva - como presunto, toucinho defumado e salsichas - concomitantemente à baixa ingestão de vitaminas (Bunin et al., 1994; Preston-Martin et al., 1996; Sarasua \& Savitz, 1994).

Além de nitratos, os vegetais contêm também as vitaminas $C$ (ácido ascórbico) e $E$ (alfatocoferol), que têm a propriedade de bloquear a reação de nitrosação. A ingestão de frutas, vegetais frescos e de cereais integrais tem papel fundamental na inibição da formação de compostos $\mathrm{N}$-nitroso, uma vez que estes fornecem, ainda, outras substâncias protetoras. Outros 
inibidores da nitrosação reconhecidos incluem uma variedade de compostos polifenólicos, amino-ácidos, selênio, sulfito e uréia, enquanto que os tiocianatos, formal deídos e haletos podem catalisar a reação. A proteção contra diferentes neoplasias conferida pelo consumo de vegetais, frutas e cereais integrais - particularmente, as de estômago, cavidade oral, esôfago, pulmão, cólon e os tumores de cérebro na infância - tem sido referida por diversos autores (Duarte \& Mídio, 1996; Inskip et al., 1995; Jacobs et al., 1995; Kohlmeier et al., 1995; Miller \& Miller, 1986; Mirvish, 1986, 1994; PrestonMartin et al., 1996; Preussman, 1984; World Cancer Research Fund/American Institute for Cancer Research, 1997).

Neste trabalho desenvolve-se uma revisão dos estudos epidemiológicos que analisaram a associação entre fatores da dieta e os tumores de cérebro em adultos, com o objetivo de descrever as associações observadas e, também, discutir os aspectos metodológicos que possam ter influência sobre os resultados obtidos.

\section{Seleção dos artigos}

Os artigos revistos foram localizados por meio de uma pesquisa na base de dados MEDLINE considerando o período 1980-1999, embora o primeiro artigo indexado publicado sobre o assunto seja de 1986 (Ahlbom et al., 1986). Para a seleção, buscou-se a combinação dos termos: brain cancer, brain neoplasm, brain tumor, diet, nutrition, food, epidemiology, adult no título, nas palavras-chave ou no resumo dos trabaIhos indexados. Foram encontrados apenas artigos publicados em inglês.

Para cada um dos artigos, foi completado um roteiro desenvolvido para descrever e analisar os aspectos metodológicos e os resultados dos estudos selecionados. Este roteiro incluía: (a) informações sobre o delineamento do estudo - local e período do estudo, base do estudo empregada (populacional ou hospitalar), métodos empregados na seleção dos casos e controles, variáveis utilizadas no pareamento de casos e controles e outros dados relativos aos procedimentos utilizados na pesquisa; (b) questões referentes à análise dos métodos empregados na avaliação do consumo de alimentos processo de coleta de dados, período de referência para a análise do consumo; análise dos dados de consumo de alimentos; (c) meios utilizados para a análise dos dados - se são explicitados a significância estatística dos resultados obtidos (valor de p), o intervalo de confiança, o nível de confiabilidade e o poder do estu- do, testes estatísticos empregados e as variáveis de confusão utilizadas no ajustamento das associações testadas.

\section{Características metodológicas dos estudos avaliados}

Foram identificados 15 artigos que analisaram o risco de tumor de cérebro considerando os fatores da dieta (Ahlbom et al., 1986; Blowers et al., 1997; Boeing et al., 1993; Burch et al., 1987; Giles et al., 1994; Hochberg et al., 1990; Hu et al., 1998, 1999; Kaplan et al., 1997; Lee et al., 1997; Mills et al., 1989; Preston-Martin \& Mack, 1991; Preston-Martin et al., 1989; Schwartzbaum et al., 1999); outros dois que avaliaram o risco de tumor de cérebro considerando, especificamente, o consumo de álcool (Hurley et al., 1996; Ryan et al., 1992); em três das publicações o enfoque era a associação destas neoplasias com substâncias encontradas na água potável para consumo (Barrett et al., 1998; Cantor et al., 1999; Steindorf et al., 1994); finalmente, Guo et al. (1994) examinaram a associação entre dieta, biomarcadores séricos e as taxas de mortalidade por tumores primários de cérebro.

Além destes, foi identificado um trabalho no qual os autores associam o incremento das taxas de tumores de cérebro com o uso do adoçante artificial aspartame (Olney et al., 1996) e também mencionadas duas cartas relativas a este artigo (Flamm, 1997; Koestner, 1997).

Houve investigações que deram origem a duas publicações, como nos artigos de Giles et al. (1994) e Hurley et al. (1996); Boeing et al. (1993) e Steindorf et al. (1994); Preston-Martin $\&$ Mack (1991) e Preston-Martin et al. (1989).

Algumas das investigações descritas fizeram parte dos dez estudos caso-controle desenvolvidos em colaboração com o Surveillance of Environmental Aspects Related to Cancer in Humans (SEARCH), programa da International Agency for Research on Cancer (IARC) (Boeing et al., 1993; Giles et al., 1994; Hurley et al., 1996; Ryan et al., 1992; Steindorf et al., 1994).

As características metodológicas dos estudos analisados estão descritas nas Tabelas $1 \mathrm{e}$ 2. Dos estudos analisados, dez eram caso-controle de base populacional (Blowers et al., 1997; Boeing et al., 1993; Cantor et al., 1999; Giles et al., 1994; Hurley et al., 1996; Lee et al., 1997; Preston-Martin \& Mack, 1991; Preston-Martin et al., 1989; Ryan et al., 1992; Steindorf et al., 1994), outros sete, eram caso-controle de base hospitalar (Ahlbom et al., 1986; Burch et al., 1987; Hochberg et al., 1990; Hu et al., 1998, 1999; Kaplan et al., 1997; Schwartzbaum et al., 
Tabela 1

Características metodológicas dos estudos que analisam a associação entre dieta e tumores de cérebro em adultos (estudos realizados entre 1986-1999).

\begin{tabular}{|c|c|c|c|c|c|}
\hline Referência & $\begin{array}{l}\text { Local e período } \\
\text { do estudo }\end{array}$ & $\begin{array}{l}\text { Desenho e base } \\
\text { de estudo }\end{array}$ & $\begin{array}{l}\text { Origem e critérios de } \\
\text { seleção dos casos } 1\end{array}$ & Origem dos controles & Comentários \\
\hline Hu et al., 1999 & $\begin{array}{l}\text { Heilongjiang, } \\
\text { China, } \\
\text { 1993-1995 }\end{array}$ & $\begin{array}{l}\text { Caso-controle, } \\
\text { base hospitalar }\end{array}$ & $\begin{array}{l}\text { Casos primários incidentes } \\
\text { de gliomas e meningiomas } \\
\text { diagnosticados em } \\
\text { seis hospitais }\end{array}$ & $\begin{array}{l}\text { Internados nos mesmos } \\
\text { hospitais dos casos nas } \\
\text { clínicas de Cirurgia Geral, } \\
\text { Urologia e O rtopedia; } \\
\text { pareamento individual por } \\
\text { sexo, idade e residência }\end{array}$ & Tamanho reduzido da amostra \\
\hline $\begin{array}{l}\text { Schwartzbaum } \\
\text { et al., } 1999\end{array}$ & $\begin{array}{l}\text { Ohio, } \\
\text { Estados Unidos, } \\
\text { 1993-1996 }\end{array}$ & $\begin{array}{l}\text { Caso-controle, } \\
\text { base hospitalar, } \\
\text { estudo-piloto }\end{array}$ & $\begin{array}{l}\text { Casos de gliomas operados } \\
\text { no Departamento de } \\
\text { Neurocirurgia no The O hio } \\
\text { State University Hospital }\end{array}$ & $\begin{array}{l}\text { Indivíduos admitidos no } \\
\text { mesmo hospital para cirurgia } \\
\text { ortopédica ou ginecológica; } \\
\text { pareamento individual por } \\
\text { raça, sexo e idade }\end{array}$ & Tamanho reduzido da amostra \\
\hline $\begin{array}{l}\text { Cantor et al., } \\
1999\end{array}$ & $\begin{array}{l}\text { lowa, } \\
\text { Estados Unidos, } \\
\text { 1984-1987 }\end{array}$ & $\begin{array}{l}\text { Caso-controle, } \\
\text { base populacional }\end{array}$ & $\begin{array}{l}\text { Casos novos diagnosticados } \\
\text { com glioma identificados } \\
\text { pelo registro de saúde do } \\
\text { Estado de lowa }\end{array}$ & $\begin{array}{l}\text { Selecionados aleatoriamente } \\
\text { a partir do registro de } \\
\text { licenças para motoristas } \\
\text { (<65 anos) e do US Health } \\
\text { Care Financial Administration } \\
\text { ( } \geq 65 \text { anos); pareamento por } \\
\text { freqüência por idade e sexo }\end{array}$ & $\begin{array}{l}74,4 \% \text { dos casos tiveram } \\
\text { substitutos como } \\
\text { respondentes }\end{array}$ \\
\hline
\end{tabular}

\begin{tabular}{|c|c|c|c|}
\hline $\begin{array}{l}\text { Barrett et al., } \\
1998\end{array}$ & $\begin{array}{l}\text { Yorkshire, } \\
\text { Inglaterra, } \\
1975-1994\end{array}$ & Estudo ecológico & $\begin{array}{l}\text { Casos registrados de tumor } \\
\text { de cérebro ocorridos em } \\
148 \text { zonas de abastecimento } \\
\text { de água. }\end{array}$ \\
\hline
\end{tabular}

Hu et al., 1998 Heilongjiang, Caso-controle, China, 1989-1995 base hospitalar

Casos primários incidentes de gliomas diagnosticados em seis hospitais
Blowers et al., 1997

Kaplan et al., 1997
Tel Hashomer,
Israel,

1987-1991
Caso-controle, base populacional 1986-1988

\section{Caso-controle, base hospitalar}

Casos incidentes de glioma em mulheres residentes no Condado de Los Angeles, identificados pelo registro do Programa de Vigilância em Câncer da Califórnia

Pacientes diagnosticados com tumor de cérebro em um hospital
Internados nos mesmos hospitais dos casos nas clínicas de Cirurgia Geral, Urologia e Ortopedia; pareamento individual por sexo, idade e área de residência

Vizinhos dos casos pareados por idade e raça

Um caso selecionado de uma lista de amigos dos casos e outro a partir de pacientes internados na clínica de O rtopedia do mesmo hospital; pareamento individual por idade, sexo e origem étnica
O s nitratos não devem ser os únicos fatores associados aos tumores de cérebro; provavelmente outros fatores não conhecidos, como por exemplo, o teor de pesticidas e outros químicos na água, podem contribuir para o desenvolvimento dos tumores de cérebro

0 estudo não foi desenhado com o intuito de investigar o consumo de alimentos; dados se referem ao consumo de poucos vegetais e frutas comumente consumidos na região à época do estudo

A generalização dos achados é limitada pois o estudo só incluiu os casos em condições de responder ao questionário (26\% dos casos elegíveis para a pesquisa

Possível viés de memória deve ter sido reduzido em parte pelo uso de substitutos em controles dos casos cujas entrevistas eram com substitutos; proporção elevada de não-resposta entre os casos; estimativa do consumo de nitratos foi incompleta pois não estimou a quantidade proveniente da água de beber 
Tabela 1 (continuação)

\begin{tabular}{|c|c|c|c|c|c|}
\hline Referência & $\begin{array}{l}\text { Local e período } \\
\text { do estudo }\end{array}$ & $\begin{array}{l}\text { Desenho e base } \\
\text { de estudo }\end{array}$ & $\begin{array}{l}\text { Origem e critérios de } \\
\text { seleção dos casos }\end{array}$ & Origem dos controles & Comentários \\
\hline Lee et al., 1997 & $\begin{array}{l}\text { San Francisco, } \\
\text { Estados Unidos, } \\
\text { 1991-1994 }\end{array}$ & $\begin{array}{l}\text { Caso-controle, } \\
\text { base populacional }\end{array}$ & $\begin{array}{l}\text { Casos incidentes de glioma, } \\
\text { identificados através do } \\
\text { Northern California Cancer } \\
\text { Center }\end{array}$ & $\begin{array}{l}\text { Selecionados por método } \\
\text { aleatório utilizando o } \\
\text { número de telefone; } \\
\text { pareamento por freqüência } \\
\text { poridade, sexo e raça }\end{array}$ & $\begin{array}{l}\text { Baixas taxas de adesão entre } \\
\text { os controles; alta proporção } \\
\text { de respondentes substitutos } \\
\text { entre os casos }\end{array}$ \\
\hline $\begin{array}{l}\text { Hurley et al., } \\
1996\end{array}$ & $\begin{array}{l}\text { Melbourne, } \\
\text { Austrália, } \\
\text { 1987-1991 }\end{array}$ & $\begin{array}{l}\text { Caso-controle, } \\
\text { base populacional }\end{array}$ & $\begin{array}{l}\text { Registros de } 14 \text { hospitais } \\
\text { com clínica de N eurocirurgia }\end{array}$ & $\begin{array}{l}\text { Amostra aleatória de } 409 \\
\text { indivíduos, obtida no } \\
\text { registro eleitoral e residentes } \\
\text { na mesma área dos casos; } \\
\text { pareamento individual por } \\
\text { sexo e idade }\end{array}$ & $\begin{array}{l}\text { Possível viés de informação; } \\
\text { altas taxas de não-resposta } \\
\text { entre os casos e controles }\end{array}$ \\
\hline Giles et al., 1994 & $\begin{array}{l}\text { Melbourne, } \\
\text { Austrália, } \\
\text { 1987-1991 }\end{array}$ & $\begin{array}{l}\text { Caso-controle, } \\
\text { base populacional }\end{array}$ & $\begin{array}{l}\text { Registros de } 14 \text { hospitais } \\
\text { com clínica de N eurocirurgia }\end{array}$ & $\begin{array}{l}\text { Amostra aleatória de } 409 \\
\text { indivíduos, obtida no } \\
\text { registro eleitoral e residentes } \\
\text { na mesma área dos casos; } \\
\text { pareamento individual por } \\
\text { sexo e idade }\end{array}$ & $\begin{array}{l}\text { Análises excluindo os } \\
\text { substitutos ou controladas por } \\
\text { este fator não alteraram as } \\
\text { odds ratio estimadas e seus } \\
\text { níveis de significância } \\
\text { estatística }\end{array}$ \\
\hline Guo et al., 1994 & $\begin{array}{l}\text { Área rural } \\
\text { da China, } \\
\text { 1973-1975; } 1983\end{array}$ & Estudo ecológico & $\begin{array}{l}\text { Taxa de mortalidade por } \\
\text { tumor primário de cérebro, } \\
\text { variando entre } 0 \text { e } 4,0 / 1.000\end{array}$ & - & $\begin{array}{l}\text { Defasagem de tempo entre a } \\
\text { informação sobre as taxas de } \\
\text { mortalidade por tumores de } \\
\text { cérebro (1973-1975) e os } \\
\text { dados sobre consumo de } \\
\text { alimentos (1983) }\end{array}$ \\
\hline $\begin{array}{l}\text { Steindorf et al., } \\
1994\end{array}$ & $\begin{array}{l}\text { Alemanha, } \\
\text { 1987-1988 }\end{array}$ & $\begin{array}{l}\text { Caso-controle, } \\
\text { base populacional }\end{array}$ & $\begin{array}{l}\text { Casos de tumores primários } \\
\text { de cérebro provenientes } \\
\text { de duas clínicas de } \\
\text { Neurocirurgia da área } \\
\text { de estudo }\end{array}$ & $\begin{array}{l}\text { Selecionados aleatoriamente } \\
\text { dos registros residenciais } \\
\text { da área de estudo; } \\
\text { pareamento por freqüência } \\
\text { separadamente para cada } \\
\text { tipo histológico, por sexo } \\
\text { e idade }\end{array}$ & $\begin{array}{l}\text { A água não é a única fonte de } \\
\text { compostos N-nitroso; é difícil } \\
\text { separar o efeito das diversas } \\
\text { fontes }\end{array}$ \\
\hline $\begin{array}{l}\text { Boeing et al., } \\
1993\end{array}$ & $\begin{array}{l}\text { Alemanha, } \\
\text { 1987-1988 }\end{array}$ & $\begin{array}{l}\text { Caso-controle, } \\
\text { base populacional }\end{array}$ & $\begin{array}{l}\text { Casos de tumores primários } \\
\text { de cérebro provenientes } \\
\text { de duas clínicas de } \\
\text { Neurocirurgia da área } \\
\text { de estudo }\end{array}$ & $\begin{array}{l}\text { Selecionados aleatoriamente } \\
\text { dos registros residenciais } \\
\text { da área de estudo; } \\
\text { pareamento por freqüência } \\
\text { separadamente para cada } \\
\text { tipo histológico, por sexo } \\
\text { e idade }\end{array}$ & $\begin{array}{l}\text { A nálises excluindo os } \\
\text { respondentes substitutos não } \\
\text { mostraram diferenças } \\
\text { substanciais }\end{array}$ \\
\hline Ryan et al., 1992 & $\begin{array}{l}\text { Adelaide, } \\
\text { Austrália, } \\
\text { 1987-1990 }\end{array}$ & $\begin{array}{l}\text { Caso-controle, } \\
\text { base populacional }\end{array}$ & $\begin{array}{l}\text { Casos de tumores primários } \\
\text { de cérebro e das meninges } \\
\text { notificados por todos os } \\
\text { neurocirurgiões e registrados } \\
\text { nos registros de câncer da } \\
\text { Região Metropolitana de } \\
\text { Adelaide }\end{array}$ & $\begin{array}{l}\text { Selecionados da lista de } \\
\text { eleitores através de seleção } \\
\text { sistemática; pareamento por } \\
\text { freqüência, tomando como } \\
\text { base a distribuição de casos } \\
\text { incidentes de tumor de } \\
\text { cérebro do Registro Central } \\
\text { de Câncer para 1984-1985; } \\
\text { considerou a idade, o sexo } \\
\text { e o local de residência }\end{array}$ & $\begin{array}{l}\mathrm{N} \text { ão encontrou diferenças } \\
\text { importantes quando análises } \\
\text { em separado foram feitas para } \\
\text { entrevistas com os casos- } \\
\text { índices e com substitutos ou } \\
\text { auxiliares; pequeno número de } \\
\text { casos gerando estratos muito } \\
\text { reduzidos; dificuldades de } \\
\text { estimar as complexas } \\
\text { exposições de fatores } \\
\text { ambientais }\end{array}$ \\
\hline $\begin{array}{l}\text { Preston-M artin } \\
\& \text { Mack, } 1991 \\
\text { Preston-Martin } \\
\text { et al., } 1989\end{array}$ & $\begin{array}{l}\text { Los Angeles, } \\
\text { Estados Unidos, } \\
1980-1984\end{array}$ & $\begin{array}{l}\text { Caso-controle, } \\
\text { base populacional }\end{array}$ & $\begin{array}{l}\text { Homens brancos e negros } \\
\text { com glioma ou meningioma } \\
\text { com registro no Programa } \\
\text { de Vigilância em Câncer de } \\
\text { Los Angeles }\end{array}$ & $\begin{array}{l}\text { Selecionados entre os } \\
\text { vizinhos dos casos; } \\
\text { pareamento individual por } \\
\text { raça e idade }\end{array}$ & $\begin{array}{l}\text { As informações sobre dieta e } \\
\text { sobre a exposição aos } \\
\text { compostos } \mathrm{N} \text {-nitroso } \\
\text { formados endogenamente } \\
\text { foram incompletas porque o } \\
\text { enfoque do estudo era sobre } \\
\text { as exposições ocupacionais }\end{array}$ \\
\hline
\end{tabular}

(continua) 
Tabela 1 (continuação)

\begin{tabular}{|c|c|c|c|c|c|}
\hline Referência & $\begin{array}{l}\text { Local e período } \\
\text { do estudo }\end{array}$ & $\begin{array}{l}\text { Desenho e base } \\
\text { de estudo }\end{array}$ & $\begin{array}{l}\text { Origem e critérios de } \\
\text { seleção dos casos }\end{array}$ & Origem dos controles & Comentários \\
\hline $\begin{array}{l}\text { Hochberg et al., } \\
1990\end{array}$ & $\begin{array}{l}\text { Boston, } \\
\text { Providence e } \\
\text { Baltimore, } \\
\text { Estados Unidos, } \\
\text { 1977-1981 }\end{array}$ & $\begin{array}{l}\text { Caso-controle, } \\
\text { base hospitalar }\end{array}$ & $\begin{array}{l}\text { Casos novos de glioblastoma } \\
\text { identificados em hospitais } \\
\text { de três cidades }\end{array}$ & $\begin{array}{l}\text { Selecionados de uma lista } \\
\text { de amigos dos casos, } \\
\text { excluídos parentes com } \\
\text { laços de consangüinidade; } \\
\text { pareamento individual por } \\
\text { sexo, idade e local de } \\
\text { residência }\end{array}$ & $\begin{array}{l}\text { A escolha da análise } \\
\text { estratificada propiciou } \\
\text { pequena redução no poder } \\
\text { do estudo; baixos níveis de } \\
\text { participação entre os casos; } \\
\text { apreciável proporção de } \\
\text { respondentes substitutos } \\
\text { entre os casos ( } 20 \%) \text { mas não } \\
\text { entre os controles ( } 2 \%) \text {; } \\
\text { possibilidade de } \\
\text { superpareamento e viés de } \\
\text { seleção na escolha de amigos } \\
\text { como controles levando a } \\
\text { tendenciosidades nas } \\
\text { informações que incluem } \\
\text { hábitos sociais }\end{array}$ \\
\hline Mills et al., 1989 & $\begin{array}{l}\text { Califórnia, } \\
\text { Estados Unidos, } \\
1976-1982\end{array}$ & Coorte & $\begin{array}{l}\text { Casos incidentes de } \\
\text { astrocitomas, glioblastomas } \\
\text { e meningiomas detectados } \\
\text { pelo Programa de Vigilância } \\
\text { em Câncer de Los Angeles } \\
\text { e San Francisco }\end{array}$ & $\begin{array}{l}\text { População de estudo } \\
\text { constituída por } 34.000 \\
\text { Adventistas do Sétimo Dia, } \\
\text { brancos não-hispânicos }\end{array}$ & $\begin{array}{l}\text { Pequeno número de casos; } \\
\text { falta informação sobre } \\
\text { diversos fatores de risco } \\
\text { associados aos tumores de } \\
\text { cérebro }\end{array}$ \\
\hline $\begin{array}{l}\text { Burch et al., } \\
1987\end{array}$ & $\begin{array}{l}\text { Ontário, Canadá, } \\
\text { 1979-1982 }\end{array}$ & $\begin{array}{l}\text { Caso-controle, } \\
\text { base hospitalar }\end{array}$ & $\begin{array}{l}33 \text { hospitais com serviço de } \\
\text { Neurologia e Neurocirurgia } \\
\text { da área de estudo }\end{array}$ & $\begin{array}{l}\text { Indivíduos admitidos em } \\
\text { qualquer outro hospital da } \\
\text { área por outro motivo } \\
\text { diferente de câncer; sempre } \\
\text { do hospital mais próximo da } \\
\text { residência de cada caso; } \\
\text { pareamento individual por } \\
\text { sexo, ano de nascimento, } \\
\text { área de residência, estado } \\
\text { marital e data do diagnóstico } \\
\text { ou do óbito }\end{array}$ & $\begin{array}{l}\text { Uso de respondentes } \\
\text { substitutos; inclusão de casos } \\
\text { diagnosticados anos antes da } \\
\text { entrevista }\end{array}$ \\
\hline $\begin{array}{l}\text { Ahlbom et al., } \\
1986\end{array}$ & $\begin{array}{l}\text { Estocolmo e } \\
\text { Upsala, Suécia, } \\
\text { 1989-1981 }\end{array}$ & $\begin{array}{l}\text { Caso-controle, } \\
\text { base hospitalar }\end{array}$ & $\begin{array}{l}\text { Pacientes com diagnóstico } \\
\text { de astrocitoma } \\
\text { supratentorial internados } \\
\text { nos departamentos de } \\
\text { Neurocirurgia de dois } \\
\text { hospitais em duas cidades }\end{array}$ & $\begin{array}{l}\text { Controles populacionais } \\
\text { selecionados nos registros } \\
\text { paroquiais; controles clínicos } \\
\text { selecionados entre os } \\
\text { pacientes tratados no } \\
\text { mesmo departamento dos } \\
\text { casos (N eurocirurgia), } \\
\text { pareamento individual por } \\
\text { sexo e data de nascimento; } \\
\text { controles clínicos não foram } \\
\text { pareados }\end{array}$ & $\begin{array}{l}\text { Uso de substitutos; tamanho } \\
\text { limitado da amostra; } \\
\text { comparação entre casos e } \\
\text { controles clínicos pode levar à } \\
\text { subestimação do efeito de } \\
\text { alguns fatores, por que dentre } \\
\text { os controles havia casos de } \\
\text { meningioma que podem ter } \\
\text { fatores etiológicos em comum } \\
\text { com os astrocitomas }\end{array}$ \\
\hline
\end{tabular}

1 todos os autores relatam que os casos foram histologicamente confirmados, exceto Mills et al. (1989) e Ahlbom et al. (1986).

1999), um era estudo de coorte prospectivo (Mills et al., 1989) e dois, estudos ecológicos (Barrett et al., 1997; Guo et al., 1994).

O período dos estudos variou entre 1973 taxas de mortalidade, Guo et al. (1994) - e 1996 - casos incidentes de gliomas, Schwartzbaum et al. (1999). À exceção dos artigos de Burch et al. (1987) e Guo et al. (1994), foram analisados, nas investigações estudadas, casos primários incidentes de tumor de cérebro. Burch et al. (1987) incluíram na casuística indivíduos diagnosticados entre 1977 e 1981, embora o perío- do de levantamento de dados tenha sido entre 1979 e 1982.

Na maioria dos estudos a idade dos casos investigados variou, em geral, de cerca de 20 a aproximadamente 75 anos, entretanto, Hochberg et al. (1990) investigaram casos de tumor de cérebro com idades entre 15 e 81 anos ( Tabela 2).

A escolha dos controles nos estudos de base populacional foi realizada com a utilização de método aleatório de seleção através do número de telefone (Lee et al., 1997); com o uso 
Características dos casos e controles investigados nos estudos sobre dieta e tumores de cérebro em adultos (estudos realizados entre 1986-1999).

\begin{tabular}{|c|c|c|c|c|c|}
\hline \multirow[t]{2}{*}{ Referência } & \multirow[t]{2}{*}{$\begin{array}{l}\text { Número de casos; } \\
\text { faixa etária }\end{array}$} & \multirow[t]{2}{*}{$\begin{array}{l}\text { Número de } \\
\text { controles }\end{array}$} & \multicolumn{3}{|c|}{$\begin{array}{l}\text { Representatividade dos casos e dos controles } \\
\text { Taxa de resposta }\end{array}$} \\
\hline & & & casos & controles & Uso de respondentes substitutos \\
\hline Hu et al., 1999 & $\mathrm{n}=129 ; 20-74$ anos & $n=258$ & $100 \%$ & $100 \%$ & não inclui \\
\hline $\begin{array}{l}\text { Schwartzbaum et al., } \\
1999\end{array}$ & $\begin{array}{l}n=40 ; \text { mediana da } \\
\text { idade }=52,5 \text { anos }\end{array}$ & $n=48$ & $95 \%$ & $92 \%$ & não inclui \\
\hline Cantor et al., 1999 & $\mathrm{n}=291 ;$ maiores de 40 anos & $\mathrm{n}=1.983$ & $91 \%$ & $\begin{array}{c}81,8 \% \\
(<65 \text { anos }) \\
\quad 79,5 \% \\
(\geq 65 \text { anos })\end{array}$ & $74,4 \%$ (entre os casos) \\
\hline Barrett et al., 1998 & $n=3.441$ & $\begin{array}{l}\text { população da } \\
\text { área: } 3,2 \text { milhões }\end{array}$ & - & - & - \\
\hline Hu et al., 1998 & $\begin{array}{l}n=218 ; \text { idade média: } \\
\text { homens }=39,2 \text { anos, } \\
\text { mulheres }=40,3\end{array}$ & $n=436$ & $100 \%$ & $100 \%$ & não inclui \\
\hline Blowers et al., 1997 & $\mathrm{n}=94 ; 25-74$ anos & $n=94$ & $26 \%$ & - & - \\
\hline Kaplan et al., 1997 & $\mathrm{n}=139 ; 18-75$ anos & $n=278$ & $77 \%$ & - & $21,6 \%$ (em casos e controles) \\
\hline Lee et al., 1997 & $\mathrm{n}=434 ;$ maiores de 20 anos & $n=434$ & $83 \%$ & $63 \%$ & $46 \%$ dos casos \\
\hline $\begin{array}{l}\text { Hurley et al., 1996; } \\
\text { Giles et al., } 1994\end{array}$ & $\mathrm{n}=416 ; 20-70$ anos & $n=409$ & $66 \%$ & $64,7 \%$ & $43,7 \%$ (entre os casos) \\
\hline $\begin{array}{l}\text { Steindorf et al., 1994; } \\
\text { Boeing et al., } 1993\end{array}$ & $\mathrm{n}=226 ; 25-75$ anos & $n=418$ & $98 \%$ & $72 \%$ & $\begin{array}{l}12 \% \text { entre os casos; } 2,63 \% \\
\text { entre os controles }\end{array}$ \\
\hline Ryan et al., 1992 & $\mathrm{n}=170 ; 25-74$ anos & $n=417$ & $80 \%$ & $62,93 \%$ & $\begin{array}{l}\text { casos: } 24,7 \% \text { substitutos: } \\
16,5 \% \text { entrevistas assistidas; } \\
\text { controles: } 0,5 \% \text { substitutos e } \\
6 \% \text { entrevistas assistidas }\end{array}$ \\
\hline $\begin{array}{l}\text { Preston-Martin } \\
\& \text { Mack, 1991; } \\
\text { Preston-M artin et al., } 1989\end{array}$ & $n=272 ; 25-69$ anos & $n=272$ & $56,9 \%$ & -1 & não inclui \\
\hline Hochberg et al., 1990 & $\mathrm{n}=160 ; 15-81$ anos & $n=125$ & $69 \%$ & $87 \%$ & $\begin{array}{l}20 \% \text { dos casos e } 2 \% \\
\text { dos controles }\end{array}$ \\
\hline Mills et al., 1989 & $\begin{array}{l}\mathrm{n}=31 ; \text { maiores de } \\
25 \text { anos em } 1976\end{array}$ & $\begin{array}{l}193.703 \\
\text { pessoas-ano }\end{array}$ & - & - & - \\
\hline Burch et al., 1987 & $\mathrm{n}=215 ; 25-80$ anos & $n=215$ & $65,6 \%$ & $52,4 \%$ & $\begin{array}{l}315 \text { substitutos entre os casos } \\
\text { e controles }\end{array}$ \\
\hline Ahlbom et al., 1986 & $\mathrm{n}=78 ; 20-75$ anos & $n=289$ & $85,7 \%$ & $92,3 \%$ & 23 indivíduos \\
\hline
\end{tabular}

1 foram identificados e entrevistados 272 controles, embora tenham sido entrevistados 277 casos.

2 quando eram entrevistados substitutos dos casos, procurou-se entrevistar substitutos dos controles; informação sobre dieta em $52,6 \%$ dos pares de caso-controle incluídos no estudo.

de listas de registros de licenças para condução de veículos, de usuários de sistema de atenção à saúde (Cantor et al., 1999), registro eleitoral (Giles et al., 1994; Hurley et al., 1996; Ryan et al., 1992), registro residencial (Boeing et al., 1993; Steindorf et al., 1994) e vizinhos (Blowers et al., 1997; Preston-Martin \& Mack, 1991; Preston-Martin et al., 1989).

Nos estudos de base hospitalar, a seleção dos controles utilizou pacientes internados nos mesmos hospitais em que os casos foram identificados nas clínicas de Cirurgia Geral, Urologia, Ortopedia, Neurocirurgia e outras não especificadas. Dois dos estudos utilizaram como controles amigos dos casos (Hochberg et al., 1990; Kaplan et al., 1997).

O número de controles por caso variou entre um (Burch et al., 1987; Preston-Martin \& Mack, 1991; Preston-Martin et al., 1989) e 6,5 (Cantor et al., 1999). Ahlbom et al. (1986) e Ka- 
plan et al. (1997), utilizaram controles clínicos e controles populacionais, variando o número total de casos anal isados entre 31 (Mills et al., 1989) e 434 (Lee et al., 1997).

Quanto ao tipo de pareamento, cinco estudos empregaram o pareamento por freqüência (Boeing et al., 1993; Cantor et al., 1999; Lee et al., 1997; Ryan et al., 1992; Steindorf et al., 1994), tendo os demais estudos utilizado o pareamento individual (Tabela 1 ).

Hu et al. (1999), não relataram recusas entre os casos e controles selecionados; Blowers et al. (1997), mostraram as menores taxas de resposta entre os casos (26,0\%) e Burch et al . (1987) as menores taxas de resposta entre controles (52,4\%). Nos estudos restantes estas taxas oscilaram entre 63,0\% - controles em Ryan et al. (1992) e 98,0\% - casos em Boeing et al. (1993); Steindorf et al. (1994) - (Tabela 2).

Respondentes substitutos foram entrevistados em oito das pesquisas incluídas nesta análise; a proporção de respondentes substitutos para os casos oscilou entre $12,0 \%$ (Boeing et al., 1993; Steindorf et al., 1996) e 74,4\% (Cantor et al., 1999). Para os controles foram utilizados substitutos nas entrevistas em proporções que variaram entre 0,5\% (Ryan et al., 1992) e 21,6\% (Kaplan et al., 1997) (Tabela 2).

Para o levantamento de dados sobre o consumo alimentar, sete estudos aplicaram questionários de freqüência do consumo de alimentos (Boeing et al., 1993; Giles et al., 1994; Hu et al., 1999; Hurley et al., 1996; Kaplan et al., 1997; Lee et al., 1997; Schwartzbaum et al., 1999). Os demais trabalhos relatam a utilização de questionário estruturado para a obtenção de dados sobre dieta.

Hu et al. (1999), Kaplan et al. (1997) e Schwartzbaum et al. (1999) obtiveram informações sobre a ingestão de alimentos de consumo geral da população, mas a maioria dos artigos revisados privilegiou a investigação do consumo de alimentos associados aos compostos $\mathrm{N}$-nitroso e às vitaminas antioxidantes, além das bebidas alcoólicas. As informações sobre o consumo de alimentos eram relativas a períodos anteriores ao diagnóstico tendo em vista a redução de tendenciosidades geradas pela alteração dos hábitos alimentares devido aos sintomas da doença. Este período variou entre o ano anterior à cirurgia (Hu et al., 1998, 1999; Schwartzbaum et al., 1999) até dez anos anteriores ao diagnóstico (Kaplan et al., 1997). Constituem exceção os dados analisados por Guo et al. (1994), nos quais as informações referentes ao consumo de vegetais e de bebida alcoólica foram obtidas em 1983, enquanto que as taxas de mortalidade por tumor primá- rio de cérebro, consideradas como variável dependente no estudo, são do período 1973-1975.

A coleta de dados foi feita através de entrevistas pessoais (Blowers et al., 1997; Boeing et al., 1993; Hu et al., 1998, 1999; Kaplan et al., 1997; Lee et al., 1997; Preston-Martin \& Mack, 1991; Preston-Martin et al.,1989; Schwartzbaum et al., 1999) ou questionários enviados pelo correio (Ahlbom et al., 1986; Giles et al., 1994; Hochberg et al., 1990; Hurley et al., 1996; Mills et al., 1989; Ryan et al., 1992) e complementados por informações obtidas por telefone (Ahl bom et al., 1986; Hochberg et al., 1990; Preston-Martin \& Mack, 1991; Preston-Martin et al., 1989).

\section{Associação entre dieta e câncer}

Fatores da dieta e aumento do risco para tumor de cérebro

Na Tabela 3 são apresentadas as associações positivas observadas entre fatores da dieta e tumores de cérebro. Os alimentos que apresentaram aumento do risco para tumores de cérebro foram o toucinho defumado (bacon) e outras conservas de carne, por exemplo: peixe salgado, carne enlatada e presunto (Ahlbom et al., 1986; Blowers et al., 1997; Boeing et al., 1993; Giles et al., 1994; Hu et al., 1999), óleos (Giles et al., 1994), batata frita, ovos (Blowers et al., 1997), vegetais salgados (Hu et al., 1999), cerveja, vinho e bebidas alcoólicas (Burch et al., 1987; Hu et al., 1999). Outros fatores da dieta como a energia total (Schwartzbaum et al., 1999), consumo de proteínas (Kaplan et al., 1997), de retinol (Giles et al., 1994) e de compostos N-nitroso e seus precursores (Blowers et al., 1997; Boeing et al., 1993; Giles et al., 1994) também apresentaram risco de favorecer o aparecimento de tumores cerebrais. Schwartzbaum et al. (1999) observaram aumento do risco desses tumores na presença de interação entre nitritos e o $\alpha$-tocoferol.

Fatores da dieta e efeito protetor para tumores de cérebro

A Tabela 4 apresenta as associações inversas obtidas entre fatores da dieta e tumores de cérebro. Um efeito protetor para tumores de cérebro foi observado com o consumo de frutas (Burch et al., 1987; Giles et al., 1994; Hu et al., 1999), vegetais (Blowers et al., 1997; Boeing et al., 1993; Giles et al., 1994; Hu et al., 1999), pão integral (Boeing et al., 1993), peixe fresco, frango (Hu et al., 1999), ovos (Kaplan et al., 1997), 
Associações positivas observadas entre fatores da dieta e tumores de cérebro em adultos (estudos realizados entre 1986-1999).

\begin{tabular}{|c|c|c|c|c|}
\hline Fatores da dieta 1 & $O R^{2}$ & IC $95 \% 3$ & Valor de $p$ & Referência \\
\hline Peixe salgado & 50,83 & $11,20-230,90$ & - & Hu et al., 1999 \\
\hline Interação entre nitritos e $\alpha$-tocoferol & 17,40 & $1,50-198,20$ & - & Schwartzbaum et al., 1999 \\
\hline Energia total & 8,20 & - & 0,02 & Schwartzbaum et al., 1999 \\
\hline Toucinho defumado (1) & 6,60 & $1,90-22,50$ & 0,0006 & Blowers et al., 1997 \\
\hline Batata frita & 5,10 & $1,20-22,60$ & 0,001 & Blowers et al., 1997 \\
\hline Ovos 4 & 4,10 & $1,20-13,50$ & 0,005 & Blowers et al., 1997 \\
\hline Cerveja4 & 3,84 & $1,60-9,20$ & $<0,01$ & Hu et al., 1999 \\
\hline NPYR5 & 3,40 & $1,80-6,40$ & $<0,001$ & Boeing et al., 1993 \\
\hline Álcool total & 3,22 & $1,50-7,00$ & $<0,01$ & Hu et al., 1999 \\
\hline Toucinho defumado (2) & 3,08 & $1,62-5,88$ & - & Giles et al., 1994 \\
\hline Bebidas alcoólicas & 2,90 & $1,10-7,60$ & 0,01 & Hu et al., 1999 \\
\hline Cereais matinais & 2,80 & $1,20-6,50$ & 0,03 & Blowers et al., 1997 \\
\hline NDMA ${ }^{6}(1)$ & 2,80 & $1,50-5,30$ & 0,001 & Boeing et al., 1993 \\
\hline NPIP7 & 2,70 & $1,40-5,20$ & 0,004 & Boeing et al., 1993 \\
\hline Vegetais salgados & 2,54 & $1,20-5,60$ & $<0,01$ & Hu et al., 1999 \\
\hline Carne enlatada (1) & 2,51 & $1,36-4,61$ & - & Giles et al., 1994 \\
\hline Carne de porco processada & 2,30 & $1,20-4,10$ & 0,01 & Boeing et al., 1993 \\
\hline Vinho 4 & 2,14 & $1,28-3,60$ & 0,04 & Burch et al., 1987 \\
\hline Toucinho defumado (3) & 2,10 & $1,00-4,40$ & - & Ahlbom et al., 1986 \\
\hline Presunto cru ou defumado & 2,10 & $1,80-4,40$ & - & Ahlbom et al., 1986 \\
\hline $\begin{array}{l}\mathrm{N} \text { itritos provenientes de } \\
\text { carnes em conserva }\end{array}$ & 2,10 & $1,00-4,60$ & 0,07 & Blowers et al., 1997 \\
\hline Toucinho defumado frito (4) & 2,10 & $1,30-3,50$ & - & Boeing et al., 1993 \\
\hline Conservas de carnes em geral & 2,10 & $1,10-4,00$ & 0,047 & Boeing et al., 1993 \\
\hline Maçãs4 & 2,04 & $1,04-4,00$ & - & Giles et al., 1994 \\
\hline Frutas ricas em vitamina $C 4$ & 2,01 & $1,17-3,45$ & 0,01 & Kaplan et al., 1997 \\
\hline Presunto cozido & 2,00 & $1,10-3,80$ & 0,03 & Boeing et al., 1993 \\
\hline óleos em geral & 1,95 & $1,14-3,34$ & - & Giles et al., 1994 \\
\hline Proteínas & 1,94 & $1,03-3,63$ & 0,12 & Kaplan et al., 1997 \\
\hline Melões 4 & 1,87 & $1,06-3,29$ & - & Giles et al., 19948 \\
\hline NDMA ${ }^{6}(2)$ & 1,78 & $1,12-2,84$ & - & Giles et al., 1994 \\
\hline Frutas em geral 4 & 1,74 & $1,03-3,01$ & 0,03 & Kaplan et al., 1997 \\
\hline Vitamina $\mathrm{E}^{4}$ & 1,68 & $1,07-2,63$ & - & Giles et al., 1994 \\
\hline Retinol4 & 1,67 & $1,04-2,68$ & - & Giles et al., 1994 \\
\hline Carne enlatada (2) & 1,60 & $1,00-2,80$ & - & Boeing et al., 1993 \\
\hline
\end{tabular}

1 os números entre parênteses indicam produtos que apareceram em mais de 1 estudo.

$2 \mathrm{OR}=$ odds ratio.

3 IC $95 \%=$ intervalo de confiança com $95 \%$ de confiabilidade.

4 a associação com o risco de tumor de cérebro aparentemente contradiz os resultados

de outros estudos que mostraram proteção para esses tumores (ver Tabela 4), ou a literatura

científica sobre a associação de dieta e câncer em geral.

$5 \mathrm{NPYR}=\mathrm{N}$-nitrosopirrolidina.

$6 \mathrm{NDMA}=\mathrm{N}$-nitrosodimetilamina.

7 NPIP = N-nitrosopiperidina.

8 os valores apresentados nesta tabela referem-se aos homens. 
Associações inversas observadas entre fatores da dieta e tumores de cérebro em adultos (estudos realizados entre 1986-1999).

\begin{tabular}{|c|c|c|c|c|}
\hline Fatores da dieta 1 & $\mathrm{OR}^{2}$ & IC $95 \% 3$ & Valor de $p$ & Referência \\
\hline Cebola & 0,10 & $0,04-0,24$ & $<0,01$ & Hu et al., 1999 \\
\hline Melancia & 0,13 & $0,01-1,00$ & - & Burch et al., 1987 \\
\hline Cenouras & 0,14 & $0,03-0,68$ & - & Giles et al., 19944 \\
\hline Frutas em geral5 (1) & 0,15 & $0,10-0,40$ & $<0,01$ & Hu et al., 1999 \\
\hline Pimentão & 0,20 & $0,10-0,70$ & 0,005 & Blowers et al., 1997 \\
\hline Couve chinesa & 0,22 & $0,10-0,50$ & $<0,01$ & Hu et al., 1999 \\
\hline Cálcio & 0,25 & $0,10-1,10$ & 0,03 & Hu et al., 1999 \\
\hline $\begin{array}{l}\text { Frutas em geral (pelo menos } \\
126 \mathrm{~g} / \text { dia)5,6 (2) }\end{array}$ & 0,28 & $0,16-0,51$ & 0,0005 & Hu et al., 1998 \\
\hline Vegetais frescos & 0,29 & $0,10-0,70$ & $<0,01$ & Hu et al., 1999 \\
\hline Aipo & 0,30 & $0,10-0,80$ & 0,009 & Blowers et al., 1997 \\
\hline Complexo multivitamínico na gestação & 0,30 & $0,10-0,90$ & 0,001 & Blowers et al., 1997 \\
\hline Pêssegos & 0,32 & $0,14-0,71$ & - & Burch et al., 1987 \\
\hline Bananas (1) & 0,35 & $0,18-0,71$ & - & Burch et al., 1987 \\
\hline Peixe fresco & 0,38 & $0,20-0,90$ & $<0,01$ & Hu et al., 1999 \\
\hline Pão integral & 0,40 & $0,30-0,70$ & - & Boeing et al., 1993 \\
\hline Couve-flor & 0,40 & $0,17-0,93$ & - & Giles et al., 1994 \\
\hline Cerveja5 & 0,40 & $0,10-0,90$ & - & Preston-M artin et al., 1989 \\
\hline Bananas (2) & 0,41 & $0,17-0,98$ & - & Giles et al., 1994 \\
\hline Salsicha 5 & 0,44 & $0,26-0,75$ & 0,03 & Burch et al., 1987 \\
\hline Vinho branco (meningioma)5 & 0,45 & $0,24-0,84$ & - & Ryan et al., 1992 \\
\hline Vitamina $\mathrm{E}^{5}$ & 0,46 & $0,10-0,60$ & 0,01 & Hu et al., 1999 \\
\hline Batatas & 0,50 & $0,30-0,90$ & 0,018 & Boeing et al., 1993 \\
\hline $\begin{array}{l}\text { Vegetais em geral (pelo menos } \\
342,5 \mathrm{~g} / \mathrm{dia})^{6}(1)\end{array}$ & 0,51 & $0,29-0,89$ & 0,009 & Hu et al., 1998 \\
\hline Sódio (1) & 0,52 & $0,31-0,87$ & 0,02 & Kaplan et al., 1997 \\
\hline Vegetais em geral (2) & 0,53 & $0,29-0,95$ & - & Giles et al., 1994 \\
\hline Nitratos 5 & 0,53 & $0,28-0,96$ & - & Giles et al., 1994 \\
\hline Ovos 5 & 0,53 & $0,33-0,87$ & 0,02 & Kaplan et al., 1997 \\
\hline Colesterol5 & 0,53 & $0,30-0,93$ & 0,06 & Kaplan et al., 1997 \\
\hline Vinho branco (glioma) 5 & 0,53 & $0,33-0,85$ & - & Ryan et al., 1992 \\
\hline Vinho (meningiomas)5 & 0,54 & $0,30-0,97$ & - & Ryan et al., 1992 \\
\hline Laranjas & 0,56 & $0,32-0,98$ & - & Burch et al., 1987 \\
\hline Maçãs5 & 0,58 & $0,34-1,00$ & - & Burch et al., 1987 \\
\hline Vinho (gliomas) ${ }^{5}$ & 0,58 & $0,38-0,91$ & - & Ryan et al., 1992 \\
\hline Suplementos vitamínicos & 0,60 & $0,40-1,00$ & 0,02 & $\begin{array}{l}\text { Preston-Martin } \\
\& \text { Mack, } 1991\end{array}$ \\
\hline Sódio (2) & 0,69 & $0,51-0,93$ & 0,013 & Kaplan et al., 1997 \\
\hline $\begin{array}{l}\text { Interação entre colesterol } \\
\text { e compostos } \mathrm{N} \text {-nitroso }\end{array}$ & 0,71 & $0,50-1,00$ & 0,053 & Kaplan et al., 1997 \\
\hline Gordura total da dieta & 0,75 & $0,56-1,00$ & 0,047 & Kaplan et al., 1997 \\
\hline
\end{tabular}

1 os números entre parênteses indicam produtos que apareceram em mais de 1 estudo.

$2 \mathrm{OR}=$ odds ratio.

3 IC $95 \%=$ intervalo de confiança com $95 \%$ de confiabilidade.

4 valores apresentados nesta tabela referem-se às mulheres.

5 a proteção observada para tumor de cérebro aparentemente contradiz os resultados

de outros estudos que mostraram risco de tumor de cérebro (Tabela 3), ou a literatura científica sobre a associação entre dieta e câncer em geral.

6 porção estimada com base no consumo anual observado no estudo. 
cerveja (Preston-Martin et al., 1989), vinho (Ryan et al., 1992). Dentre os componentes dos alimentos com possível papel protetor foram evidenciados o cálcio, a vitamina $\mathrm{E}$ (Hu et al., 1999), o colesterol, a gordura total, o sódio e a interação entre compostos N-nitroso e colesterol (Kaplan et al., 1997). Preston-Martin et al. (1989) e Blowers et al. (1997) indicaram que o uso de suplementos vitamínicos também pode ter papel na proteção para tumores de cérebro.

Guo et al. (1994) utilizaram o coeficiente de regressão para estimar a associação entre fatores da dieta com as taxas de mortalidade de tumor de cérebro. Entre os indivíduos do sexo masculino, foram obtidos coeficientes estatisticamente significativos para o consumo de vegetais em conserva $(r=0,31 ; p=0,04$ - coeficiente ajustado), ovos ( $r=0,28 ; p=0,05)$, cerveja $(r=0,31 ; p<0,05)$ e vegetais verdes $(r=-0,29$; $p=0,05$ - coeficiente ajustado).

Blowers et al. (1997) analisaram o risco de tumor de cérebro considerando o consumo combinado de alimentos que contêm precursores de compostos $\mathrm{N}$-nitroso e inibidores da nitrosação. A hipótese subjacente é que o consumo de toucinho defumado, por exemplo, incrementaria o risco de tumor de cérebro, mas este incremento seria reduzido se o toucinho defumado fosse consumido usualmente com suco de laranja, por exemplo, cujo conteúdo de vitamina $C$ inibe a formação endógena de compostos N-nitroso. Estes autores observaram que entre as mulheres que ingeriam suco de laranja em pelo menos $50 \%$ das ocasiões em que consumiam toucinho defumado, a estimativa do risco de desenvolver tumor de cérebro não foi significativa (OR =1,5; IC 95\%: 0,7-3,2) enquanto que as que consumiam essa combinação mais raramente, apresentaram um excesso no risco de desenvolver essa neoplasia (OR = 2,5; IC 95\%: 1,1-5,5; teste de tendência $p=$ 0.01). Resultados semelhantes foram observados para o consumo de cerveja acompanhando refeições.

Lee et al. (1997), também estimaram o risco de tumor de cérebro considerando o consumo combinado de alimentos conservados, de vegetais e de frutas ricas em vitamina $C$. Os autores utilizaram as medianas como limite para classificar o consumo de fatores da dieta em alto e baixo. Comparando o grupo de homens com alto consumo de conservas e baixo consumo de vegetais e frutas (grupo de maior risco) e aqueles com baixo consumo de conservas e alto consumo de frutas e vegetais (considerado grupo de referência) obtiveram uma odds ratio $(O R)=2,0$ (IC 95\%: 1,2-3,5). Entre as mulheres esta associação não se mostrou significativa
(OR = 1,5; IC 95\%: 0,8-2,7). Estes autores encontraram a mesma relação quando consideraram o consumo de nitritos e vitamina $C$. No sexo masculino, a OR associada ao consumo aumentado de nitritos combinado com o consumo reduzido de vitamina C foi de 2,1 (IC 95\%: 1,1-3,8), igualmente não sendo observadas associações significativas no sexo feminino.

Evidências contraditórias da associação entre fatores da dieta e tumores de cérebro

Alguns dos resultados obtidos são incoerentes com a literatura científica sobre o papel de itens específicos do consumo alimentar no desenvolvimento do câncer, foi o caso da salsicha (Burch et al., 1987), do conteúdo de nitratos da dieta (Giles et al., 1994), da cerveja (PrestonMartin et al., 1989), do vinho (Ryan et al., 1992) e do conteúdo total de colesterol e gordura da dieta (Kaplan et al., 1997), para os quais foi observado o efeito protetor para tumores de cérebro (Tabela 4). Por outro lado, foram estimadas OR elevadas, significando o aumento do risco de aparecimento de tumores de cérebro para o consumo de maçã, melões, retinol, vitamina $\mathrm{E}$ (Giles et al., 1994), frutas em geral e frutas ricas em vitamina C (Kaplan et al., 1997) (Tabela 3).

Para alguns alimentos, a estimativa do risco associado aos tumores de cérebro forneceu resultados contraditórios, ou seja, em estudos diferentes, tanto foi observado o efeito protetor como o aumento do risco. Neste grupo incluem-se: ovos (Blowers et al., 1997; Kaplan et al., 1997), cerveja (Hu et al., 1999; Preston-Martin et al., 1989), vinho (Burch et al., 1987; Ryan et al., 1992), maçã (Burch et al., 1987; Giles et al., 1994), frutas em geral (Hu et al., 1998, 1999; Kaplan et al., 1997) e vitamina E (Giles et al., 1994; Hu et al., 1999) (Tabelas 3 e 4).

Associações não estatisticamente significativas entre fatores da dieta e tumores de cérebro

São listados na Tabela 5 os produtos alimentares e os demais fatores da dieta que não apresentaram associação estatisticamente significativa, quando testados para o risco de tumores de cérebro. Nessa lista incluem-se diversos produtos que se mostraram estatisticamente associados aos tumores cerebrais em outros estudos, e até num mesmo estudo quando observados em estratos diferentes. Este foi o caso de itens como toucinho defumado (Boeing et al., 1993; Burch et al., 1987; Giles et al., 1994; Preston-Martin \& Mack, 1991; Schwartzbaum et al., 1999), carne enlatada (Boeing et al., 1993; 
Burch et al., 1987; Hu et al., 1999), conservas de carne em geral (Giles et al., 1994; Kaplan et al., 1997), para os quais foram observadas associações positivas significativas (Tabela 3). Para produtos como batatas (Giles et al., 1994; Hu et al., 1999), cenouras (Giles et al., 1994; Kaplan et al., 1997), couve-flor (Giles et al., 1994), peixe fresco (Boeing et al., 1993; Giles et al., 1994; Kaplan et al., 1997) e suplementos vitamínicos (Boeing et al., 1993; M ills et al., 1989; PrestonMartin \& Mack, 1991), observaram-se associações inversas significativas com os tumores de cérebro (Tabela 4).

Foram observadas associações positivas, porém sem significância estatística no caso de produtos tais como: alho, bananas, bebidas com cafeína, chá, óleos em geral, peixe processado e sacarina. Para um outro grupo de fatores dietéticos estimou-se uma associação inversa com os tumores de cérebro em adultos, porém sem que fosse alcançada a significância estatística, como exemplo: açúcar, derivados da soja, pimentão e repolho. Para alguns dos itens relacionados não se observou associação com os tumores de cérebro em adultos, por exemplo: doces, folhas verdes, vegetais do gênero Brassica (repolho, couve-flor, brócolis) em geral, queijo, refrigerantes e beta-caroteno (Tabela 5).

Além disso, Mills et al. (1989) sugeriram que a adoção de dieta vegetariana antes dos 15 anos de idade estaria associada ao aumento do risco de meningioma ( $R R=4,19$; IC 95\%: 0,98-17,90) mas não alteraria o risco de glioma $(R R=0,65$; IC 95\%: 0,18-2,38; $p=0,75$ ).

Risco de tumor de cérebro e consumo de bebidas alcoólicas, água potável e aspartame

Burch et al. (1987) não observaram relação entre o consumo de cerveja (OR =1,18; IC 95\%: $0,77-1,18)$ e bebidas alcoólicas destiladas (OR = 1,09; IC 95\%: 0,72-1,65) e o desenvolvimento de tumores de cérebro. A relação entre o uso de álcool e o risco de tumor de cérebro não foi observada por Mills et al. (1989) (OR =0,85; IC 95\%: 0,20-3,59; $p=0,99$ ). O consumo de cerveja também não apresentou associação estatística significativa ( $R R=0,7$; IC 95\%: 0,4-1,1) com o risco de glioblastoma na investigação de Hochberg et al. (1990). Hurley et al. (1996), igualmente, não encontraram evidências de associação entre o consumo de bebida alcoólica e glioma (OR =1,02; IC 95\%: 0,64-1,62 para o consumo médio diário maior que $29,7 \mathrm{~g}$ ).

Ryan et al. (1992) observaram redução do risco de glioma e meningioma mediante o consumo de vinho, particularmente o vinho bran-
Tabela 5

Fatores da dieta não associados estatisticamente com tumores de cérebro em adultos (1986-1999).

Produtos alimentares
Açúcar ${ }^{1}$

Álcool total2,3,4

Alho3

Alimentos defumados2

Bananas 3

Banha de porcol

Batata frita 3

Batatas 1,2,3,5

Bebidas alcoólicas 2,4

Bebidas com cafeína1,3

Brócolis1,3

Cachorro quente 1,2

Café2,3

Carne enlatada $1,2,3,4$

Carnes em geral1,2,3

Cenouras 1,5

Cereais 1,3

Cereais refinados 3

Cerveja1,3,4

Chá3

Chocolates 2

Conservas de carnes em geral2,3,4

Couve-flor 5

Derivados da soja ${ }^{1}$

Doces 2

Feijões verdes1,3

Fígadol

Folhas verdes 1,2

Frutas cítricas $1,2,3$

Frutas em geral1,3,4,5

Legumes 1

Leite e derivados 3

M açãs 2,4,5

Massas brancas1,2

$M$ assas integrais1,3

Melões 1,4
Cereais integrais 3
Molho para salada 3

Nozes 2,3

Óleo de soja3

Óleos em geral3

Pão ${ }^{3}$

Peixe congelado 1

Peixe defumado2,3

Peixe enlatado 1

Peixe fresco 1,2,3,5

Peixe processado 3

Peixe salgado 3

Picles de couve chinesa ${ }^{3}$

Pimentão ${ }^{1}$

Porco 1,3

Porco defumado2

Presunto cru2

Presunto defumado 1

Q ueijo 1,2,3

Refrigerantes 1,2

Refrigerantes do tipo cola1,3

Repolho1,2

Sacarina 3

Sal2

Salame e salsichão 1

Salame/pastrami1,2,3

Salsicha defumada2

Salsicha1,3,5

Salsichão 1,2

Sopa de vegetais 1,3

Suco de frutas 2,3

Suco de vegetais 1

Suplementos vitamínicos3,5

Tomate 3

Toucinho defumado 1,2,3,4

Vegetais amarelos 1,3

Vegetais em geral2

Vegetais gênero Brassica em geral1,2
Nutrientes e não nutrientes

\section{Betacaroteno 1,2}

Colesterol1

Compostos N-nitroso totais2,3

Energia proveniente das gorduras 2

Energia proveniente das proteínas 3

Interação entre energia e vitamina C 1 Interação entre energia e $\alpha$-tocoferol 1 Interação entre energia e $\gamma$-tocoferol3 Interação entre nitritos e vitamina $\mathrm{C}^{1}$ Interação entre nitritos e $\alpha$-tocoferol2
Gordura total1
Interação entre proteínas e compostos $\mathrm{N}$-nitroso ${ }^{3}$

NDMA (N-nitrosodimetilamina) 3

$\mathrm{N}$ itratos $2,3,5$

$\mathrm{N}$ itritos 2,3

$\mathrm{N}$ itritos provenientes de carnes

em conserva3

Proteínas ${ }^{3}$

Retinol/Vitamina $\mathrm{A}^{3}$

Selênio 3

Vitamina C 1,2,3

Vitamina $\mathrm{E}^{2}$
1 observou-se associação inversa com tumores de cérebro em adultos porém não estatisticamente significativa ( $O R$ com valores $<0,9$ ).

2 não se observou associação com tumores de cérebro em adultos (OR variou entre 0,9 e 1,09 ).

3 observou-se associação positiva com tumores de cérebro em adultos, porém não estatisticamente significativa ( $\mathrm{R}$ com valores $\geq 1,1$ ).

4 foram observadas associações positivas em outros estudos ou em outros estratos do mesmo estudo (Tabela 3).

5 foram observadas associações inversas em outros estudos ou em outros estratos do mesmo estudo (Tabela 4). 
co (Tabela 4). Para glioma não foi evidenciada a presença de relação dose-resposta, mas para meningioma observaram tendência de redução da OR de acordo com o aumento do consumo médio diário de vinho branco $(O R=0,67$; 0,40 e 0,21 para o 1으, 2o e 3otercis, respectivamente).

Burch et al. (1987) observaram aumento do risco de tumor de cérebro relacionado com o consumo de vinho (OR =2,14; IC 95\%: 1,283,60; valor de $p=0,004)$. Hu et al. (1998) observaram que o risco de tumor de cérebro apresentou-se significativamente mais elevado para aqueles que tomavam bebidas alcoólicas por período igual ou maior que 21 anos $(O R=2,96$; IC 95\%: 1,24-7,06; valor de $p=0,01$ ); ou que consumiram mais de um litro de bebidas alcoólicas durante toda a vida (OR =2,73; IC 95\%: 1,06-7,08; valor de $p=0,02$ ).

A associação entre os níveis de nitrato na água potável e o risco de tumor de cérebro não foi observada por Steindorf et al. (1994): a média da concentração de nitrato na água de beber entre os casos era de 15,98mg/l e entre os controles de 16,60mg/l. Mas Barrett et al. (1998) observaram discreta elevação do risco para tumor de cérebro ( $R R=1,18$; IC 95\%: 1,08-1,30) nos grupos expostos aos mais altos níveis de nitratos provenientes da água de beber (média populacional de 29,8ml/I). De outro lado, Cantor et al. (1999) observaram uma relação doseresposta para o risco de tumor de cérebro em homens devido à duração do consumo de água clorada (OR =1,3; 1,7 e 2,5 para exposição por menos de 20 anos, entre 20 e 39 anos e 40 ou mais anos, respectivamente; $p=0,04$ ).

Olney et al. (1996) anal isaram que o incremento nas taxas de incidência dos tumores de cérebro observado nos registros de câncer norte-americanos durante as últimas décadas, poderia ser explicado inicialmente (entre 1975 e 1984), pelas facilidades introduzidas nos métodos de diagnóstico e, posteriormente (a partir de 1985) por algum outro fator ambiental amplamente disseminado na população. Estes autores sugerem que seja melhor investigado o potencial carcinogênico do adoçante artificial aspartame, o que, segundo os autores, tem grandes possibilidades de ser responsabilizado pelas taxas ascendentes de neoplasias cerebrais. Entretanto, as suposições desses autores foram veementemente refutadas por Flamm (1997) e por Koestner (1997, que contestaram a fundamentação científica das afirmações de Olney et al. (1996).

\section{Discussão}

A etiologia dos tumores de cérebro em adultos tem sido tratada na literatura científica com freqüência, especialmente a partir da década de 80 quando se constatou a elevação das suas taxas de incidência e de mortalidade, particularmente nos países industrializados. Apesar desse incremento ser creditado parcialmente à modificação dos recursos diagnósticos, a suposição de que um fator ambiental amplamente disseminado poderia ter papel no desenvolvimento dos tumores cerebrais tem estimulado a investigação do efeito dos fatores da dieta sobre essas neoplasias.

Possivelmente, o fato de ser doença rara tenha imprimido um caráter secundário aos tumores de cérebro, quando é necessário justificar a realização de investigações sobre a sua etiologia. Por outro lado, os fatores ambientais relacionados com o surgimento destes tumores são extensamente distribuídos na população em geral, resultando num possível efeito de subestimação dos riscos, o que explica, pelo menos em parte, a inconsistência observada nos estudos. Mas significa, também, a ampliação da população sob risco. Os aspectos metodológicos das pesquisas sobre tumores de cérebro e dieta devem ser explorados, pois auxiliam a compreensão dos resultados obtidos.

Limitações metodológicas dos estudos

epidemiológicos sobre tumor de cérebro

Dentre os estudos investigados, as limitações mais evidentes para a obtenção de resultados conclusivos foram: (a) tamanho reduzido da amostra (Ahlbom et al., 1986; Hu et al., 1999; Mills et al., 1989; Ryan et al., 1992; Schwartzbaum et al., 1999); (b) altas taxas de não-resposta (Blowers et al., 1997; Hochberg et al., 1990; Hurley et al., 1996; Kaplan et al., 1997) e (c) utilização de respondentes substitutos (Boeing et al., 1993; Cantor et al., 1999; Giles et al., 1994; Hochberg et al., 1990; Hurley et al., 1996; Lee et al., 1997; Ryan et al., 1992) (Tabela 1).

Como se trata de uma doença relativamente pouco incidente frente às demais localizações tumorais, o desenho de escolha para a anál ise dos tumores de cérebro tem sido o estudo de caso-controle. Nesses estudos, a estimativa das exposições passadas, freqüentemente é alvo de críticas pois está sujeita a imprecisões e a tendenciosidades advindas das limitações na capacidade de recordação dos indivíduos entrevistados, particularmente porque a doença em questão pode provocar danos às habilidades mentais onde, em muitas situa- 
ções, é necessário contar com as informações prestadas por respondentes substitutos.

Qualquer estudo que tente obter informações sobre eventos que ocorreram no passado, está sujeito às limitações da memória dos indivíduos investigados. Esta fragilidade pode ser afetada pelo intervalo de tempo desde a exposição, pelo grau de detalhe que está sendo requerido sobre o aspecto em questão, pelas características pessoais dos respondentes, pelo simbolismo e significado emocional que envolvem os eventos em estudo e se o assunto em pauta está sujeito a padrões socialmente desejáveis de reposta. Sem dúvida, estes tópicos são relevantes quando se analisa o consumo alimentar.

O viés de memória pode ocorrer de forma diferencial entre casos e controles, e vários fatores podem contribuir para isto. Os casos podem estar mais motivados a relatar possíveis exposições pregressas que os controles sadios; uma vez que a tendência do doente é, geralmente, procurar causas ou explicações para a sua condição. Os casos podem já ter tido a oportunidade de refletir sobre as exposições passadas, por exemplo, nas consultas médicas. Os hábitos alimentares freqüentemente são divulgados na mídia como relacionados com o risco de câncer, levando os doentes com tumores a fazerem uma apreciação de seu histórico alimentar (Coggon, 1991; Margetts, 1991).

Alguns estudos investigaram as diferenças entre casos e controles na capacidade de recordar o consumo de alimentos anteriormente. Lindsted \& Kuzma (1989) concluíram que não havia diferenças significativas no relato de casos incidentes de câncer e controles, após o ajuste das estimativas por fatores relacionados com a memória (por exemplo: idade, sexo e escolaridade). Wilkens et al. (1992) não observaram diferenças marcantes na capacidade de relatar a dieta do passado de casos de câncer e controles populacionais. Entretanto, estes autores sugeriram que erros de classificação diferenciais podem ocorrer, pois consideraram que o diagnóstico de câncer afeta a capacidade de recordação da dieta do passado distante.

As mudanças comportamentais devido ao diagnóstico e ao tratamento, influenciam, também, a acurácia da lembrança dos casos. As alterações no consumo de alimentos decorrentes da doença, provocando geralmente, a redução do consumo, podem levar ao relato subestimado da ingestão pregressa de alimentos. Este fenômeno poderia redundar na subestimação das verdadeiras associações positivas entre dieta e câncer e, também, indicar erroneamente o papel protetor de alguns nutrientes. Em al- guns casos é útil perguntar aos indivíduos incluídos no estudo, se eles reconhecem alterações na sua dieta após o diagnóstico, embora este tipo de informação seja subjetiva e não possa ser quantificada (Austin et al., 1994; Coggon, 1991; Holmberg et al., 1996; Margetts, 1991).

De acordo com Samet (1990) os relatos de exposições alimentares pregressas por parte de respondentes substitutos podem, eventualmente, estar menos sujeitos a tendenciosidades do que os fornecidos pelos entrevistadosíndices; por exemplo, no contexto de um estudo caso-controle sobre uma doença que leve à alteração da dieta, os substitutos poderiam informar melhor sobre a dieta pregressa do que os próprios casos, cujo relato seria influenciado pela dieta praticada após o aparecimento dos sintomas.

Embora a magnitude e a direcionalidade dos erros derivados das respostas fornecidas por respondentes substitutos não estejam muito esclarecidas, a possibilidade de sua ocorrência deve ser considerada. A participação dos respondentes substitutos pode ter introduzido importante viés nas informações levantadas e contribuído para a inconsistência dos achados. Somente Burch et al. (1987) e Kaplan et al. (1997) referiram o uso de informantes substitutos dos controles quando estes eram entrevistados para os casos, procedimento recomendado com uma forma de diminuir as classificações diferenciais incorretas (Samet, 1990; Wacholder et al., 1992). Contudo, Lee et al. (1997) observaram que a informação fornecida por um respondente substituto de um controle, poderia não ser comparável àquela que é dada por um informante substituto de um caso, pois uma doença com o impacto de um tumor cerebral poderia afetar também as pessoas próximas ao caso, modificando, também, as informações que elas podem dar sobre ele e gerando, igualmente, tendenciosidades.

Giles et al. (1994) observaram discrepâncias em seus dados quando analisaram os riscos de tumor de cérebro relacionados ao consumo de alimentos estratificados para homens e mulheres. Os autores assinalaram que estas discrepâncias poderiam ser creditadas às diferenças nos relatos dos informantes substitutos. Estes autores observaram que quando os respondentes substitutos eram as esposas, as informações sobre dieta apresentaram melhor qualidade do que quando ocorria o inverso, ou seja, nas ocasiões em que o informante substituto eram os maridos, concluindo que provavelmente, por esse motivo as estimativas dos riscos segundo o sexo foram diferenciadas. 
Hurley et al. (1996) relataram que o uso de substitutos provavelmente não proporcionou tendenciosidades importantes nas informações obtidas, tendo em vista a realização de análises em separado para os dois grupos (entrevistas com o entrevistado-índice e entrevistas com o respondente substituto). Boeing et al. (1993) também referem que a exclusão das entrevistas realizadas com substitutos na análise, não forneceu resultados substancialmente distintos das observações com base em análises que incluíram as entrevistas com respondentes substitutos. Lee et al. (1997) e Ryan et al. (1992) também não observaram diferenças importantes quando foram desenvolvidas análises para entrevistas com casos-índices e com substitutos, separadamente.

As baixas taxas de resposta dos casos e dos controles em alguns dos estudos (Tabela 2), podem ter originado viéses devidos à seleção dos indivíduos investigados, como por exemplo, a investigação de Lee et al. (1997) onde os autores descreveram a ocorrência de diferenças importantes entre os controles participantes e os que se recusaram a participar da pesquisa no que diz respeito à utilização de suplementos vitamínicos.

Problemas com a metodologia de avaliação do consumo de alimentos

Além de estar submetida ao viés de memória, a dieta constitui um conjunto complexo de exposições fortemente interrelacionadas, cuja estimativa acurada é bastante difícil de ser alcançada. Na verdade não existe uma metodologia prática e precisa para medir o consumo de alimentos, tarefa esta que envolve sempre instrumentos sujeitos a diferentes fontes de erro, por exemplo, devido à memória, ao período de referência, ou por utilizar uma lista limitada de produtos.

Quando se trata de dieta, as exposições não podem ser caracterizadas como ausentes ou presentes e a sua classificação é realizada segundo níveis de exposição, uma vez que todos os indivíduos são, teoricamente, expostos aos mesmos hipotéticos fatores causais pois todos comem gorduras, fibras, vitaminas etc., sendo a freqüência da ingestão a variação mais importante. As alterações no padrão de alimentação nem sempre são claramente identificáveis e envolvem longos períodos. Por outro lado, a estimativa do consumo de nutrientes, por exemplo, é usualmente determinada de forma indireta, baseando-se no relato do consumo de alimentos e na sua composição bioquímica (Willett, 1998).
Para explicar a ausência de associação entre dieta e câncer, uma questão essencial é a adequada seleção dos controles. Quando são selecionados indivíduos cujas dietas sejam muito semelhantes, a variabilidade inter-individual torna-se insuficiente para apreender os riscos associados. Outra explicação possível relaciona-se com o método de avaliação da dieta que, não sendo suficientemente preciso, não permite detectar diferenças entre os indivíduos investigados. O número insuficiente de indivíduos observados nos estratos de casos e controles, pode contribuir para que não sejam obtidos resultados que demonstrem associação entre fatores da dieta e câncer. Há ainda, a possibilidade de que a relação temporal entre a exposição mensurada (dieta) e a doença em estudo não esteja incluindo o período de latência. Além disso, uma associação pode não ser detectada se existirem fatores de confusão não avaliados, e que estejam relacionados com a exposição e a doença em direções opostas (Willett, 1998).

Willett (1998) assinala que em estudos de epidemiologia nutricional é comum a observação de exceções aos critérios para a consi deração de relações causais entre exposição e efeito, que incluem a força da associação, a consistência dos achados em diferentes estudos e populações, a presença de relação dose-resposta, a relação temporal apropriada, a plausibilidade biológica e a coerência com o conhecimento existente. A falta de aderência a esses critérios ocorre principalmente porque: (a) neste campo de estudo, associações verdadeiras não são, provavelmente, fortes, e riscos relativos de 0,7 ou 1,5 são potencialmente importantes porque as exposições dietéticas são muito comuns; (b) as características das populações estudadas e os diferentes desenhos de investigação podem explicar a inconsistência entre os estudos; (c) é provável que a relação dose-resposta não seja linear e, dependendo dos níveis observados ou dos valores empregados na estratificação, não se observe associação; (d) como a fisiopatologia do câncer ainda não foi suficientemente desvendada, o fato de não se conhecer completamente os processos biológicos que determinam o papel da dieta na causação do câncer, não significa a ausência de relação de causalidade envolvendo os fatores da dieta e o câncer.

Associação entre fatores da dieta e tumores de cérebro em adultos

A maioria dos estudos epidemiológicos abordando dieta e sua associação com tumores de 
cérebro, apresentam baixo poder estatístico e estimativas pouco precisas da ingestão de alimentos, o que leva freqüentemente, a achados inconsistentes. A interpretação das associações nulas ou não estatisticamente significativas entre fatores da dieta e câncer deve ser alvo de considerações, particularmente, no que diz respeito às características e às limitações das investigações que lhes deram origem.

Uma fonte que gera inconsistência nos resultados nestes estudos, é inerente à complexidade biológica das interações entre os diferentes componentes dos al imentos (nutrientes e não-nutrientes). A conjugação desta complexidade biológica com as dificuldades metodológicas pode resultar numa literatura de difícil interpretação, sendo uma das possíveis explicações para alguns dos resultados contraditórios obtidos. Provavelmente, fatores de confusão não conhecidos e outros fatores da dieta não explorados, podem ser responsáveis por algumas das associações contraditórias observadas, como por exemplo, o fato de que alguns estudos tenham atribuído às frutas o aumento no risco de tumores de cérebro (Tabela 3), bem como a associação de salsicha (Burch et al., 1987) e nitratos (Giles et al., 1994) com a proteção para este tipo de tumor (Tabela 4).

A inclusão dos nitratos (que são precursores secundários dos compostos $\mathrm{N}$-nitroso), entre as substâncias que conferem proteção contra o risco de desenvolver tumor de cérebro ( Tabela 3), pode ter relação com o fato de que as maiores fontes de nitratos sejam os vegetais (Duarte \& Mídio, 1996; Preussman, 1984). Porém, estes são, também, ricos em substâncias inibidoras da nitrosação (por exemplo, a vitamina C). Para Blowers et al. (1997) a concentração de nitritos provenientes da redução dos nitratos parece ser menor do que aquela fornecida pelas carnes em conserva. O alto conteúdo de nitratos na dieta pode indicar uma alimentação rica em vegetais, portanto, com as possíveis propriedades de inibição dos tumores de cérebro que têm sido associadas ao consumo de vegetais e frutas.

Preston-Martin \& Lijinsky (1994), salientam que a relação mais importante observada em um estudo caso-controle de base populacional foi a tendência de aumento do risco de tumores de cérebro em crianças, associado com o consumo de nitritos provenientes de carnes em conserva, e não com o conteúdo total de nitritos da dieta. Para esses autores, a explicação para este fenômeno reside no fato de que a dieta inclui nitritos originados pela redução dos nitratos na saliva, cuja mai or fonte são os vegetais. Essa parcela de nitritos apresenta-se mais diluída do que a que provém dos pequenos pedaços de carnes em conserva que permanecem no estômago por algumas horas após a ingestão, e que propicia, portanto, altas taxas de formação de compostos N-nitroso.

Por outro lado, acreditamos que o efeito protetor associado ao consumo de salsichas, pode também estar refletindo outras características dos hábitos alimentares não investigados, como por exemplo, o fato de que esses produtos são consumidos, usualmente, acompanhados de vegetais ou sucos.

Giles et al. (1994) comentaram que a associação observada entre tumores de cérebro e consumo de melão poderia estar relacionada com o alto conteúdo de citrulina nestas frutas, uma substância do grupo uréia que ocorre naturalmente e que também é precursora dos compostos $\mathrm{N}$-nitroso, embora de baixo potencial carcinogenético (Shephard et al., 1987). Adicionalmente, pode-se sugerir que as associações observadas com melões e maçãs (Tabela 3), podem ser resultado de fatores de confusão não investigados, como por exemplo, se estes itens são consumidos acompanhando refeições com alto conteúdo de carnes em conserva.

Da mesma maneira podem ser vistas as associações positivas observadas para retinol e vitamina $\mathrm{E}$ (Tabela 3), O retinol está presente em alimentos de origem animal e, portanto, pode ser relacionado aos compostos $\mathrm{N}$-nitroso. A vitamina $\mathrm{E}$ está associada às gorduras vegetais, consideradas como risco para tumor de cérebro no estudo de Giles et al. (1994).

O risco de tumor de cérebro associado à ingestão de ovos e batata frita (Tabela 3), poderia estar refletindo um grau de colinearidade com o consumo de toucinho defumado, de óleos e de gorduras em geral, particularmente, quando submetidos a altas temperaturas. A observação de aumento do risco de tumor de cérebro mediante o consumo de óleos (Giles et al., 1994) pode ser um indicativo de que outros fatores da dieta além dos compostos $\mathrm{N}$-nitroso interfeririam no desenvolvimento das neoplasias cerebrais, como por exemplo, os produtos resultantes do aquecimento excessivo dos ácidos graxos, sugerido por Boeing et al. (1993).

Schwartzbaum et al. (1999) observaram incremento no risco de glioma devido à ingestão calórica el evada; os autores especulam sobre os mecanismos envolvidos nessa relação, sugerindo que possivelmente, o efeito do alto consumo de energia está relacionado com o dano oxidativo às moléculas de DNA, provocadas pelo necessário aumento do metabolismo. Os autores apontam que viéses de várias origens podem estar presentes: o pequeno número de ca- 
sos não permitindo o ajuste das estimativas segundo as diferentes variáveis de confusão; a possibilidade de elevação do conteúdo energético da dieta dos pacientes com glioma devido ao próprio tumor; e a possível redução do consumo de calorias por parte do grupo controle.

O aumento do risco de tumores de cérebro devido ao maior consumo de proteínas (Tabela 3), observado por Kaplan et al. (1997) e também aquele vinculado com a interação entre o consumo de proteínas e de compostos N-nitroso (estatisticamente não significativa), provavelmente está relacionado com os produtos que são ricos em compostos $\mathrm{N}$-nitroso e que, quase sempre, são produtos com importante conteúdo protéico (carnes e pescados processados, por exemplo).

O achado mais surpreendente do estudo de Kaplan et al. (1997), foi a constatação da redução do risco de gliomas mediante o consumo de sódio, de colesterol e pela interação entre o consumo de colesterol e de compostos N-nitroso. Os autores consideraram que a associação inversa encontrada, poderia estar relacionada com a inibição da mutagenicidade dos compostos $\mathrm{N}$-nitroso pelos ácidos graxos, ou com seu efeito na estrutura e na função da barreira hematoencefálica, que também pode sofrer influência do colesterol. Estas observações sugerem que o alto consumo de colesterol poderia inibir o transporte de compostos N-nitroso através da barreira hematoencefálica. Para os autores, tais achados são compatíveis com a idéia de que a gordura age por meio de mecanismos específicos nos diferentes órgãos - favorecendo (como no caso das neoplasias de mama e de cólon) ou inibindo a carcinogênese.

O papel do álcool e das bebidas alcoólicas no aparecimento de tumores de cérebro é ainda questionável. Embora a cerveja seja rica em compostos $\mathrm{N}$-nitroso, os resultados dos estudos revisados não permitem definir que as bebidas alcoólicas sejam fatores de risco para estas neoplasias.

Hu et al. (1998) que observaram aumento do risco de tumores de cérebro com a ingestão de álcool por pelo menos 21 anos, ou em quantidades maiores que um litro durante toda a vi$\mathrm{da}$, assinalaram que o uso de controles hospitalares poderia ter introduzido alguma tendenciosidade nas associações observadas entre consumo de bebida alcoólica e glioma, se as condições que levaram à internação desses controles propiciassem a redução do consumo de álcool. Mas estes autores sugerem que, possivel mente, os resultados não foram determinados pelos critérios de seleção dos controles, pois um outro estudo caso-controle enfocando o câncer de pulmão que usou os mesmos critérios para a escolha dos controles, não revelou associação com o consumo de álcool.

No estudo ecológico realizado por Guo et al. (1994) além das limitações usual mente encontradas em estudos ecológicos - pois os dados analisados eram médias populacionais e não expressavam as exposições individuais devem ser apontados alguns aspectos importantes, como a seqüência temporal utilizada, uma vez que os dados de mortalidade por tumor de cérebro referem-se aos anos de 1973-75 e os dados sobre consumo de alimentos foram coletados em 1983. Os autores assinalaram que, durante o período de estudo, observou-se uma relativa estabilidade nas condições de vida nas regiões rurais da China e consideraram improvável a ocorrência de mudanças substanciais nos hábitos alimentares, nos outros fatores de exposição estudados e nas taxas de mortalidade por tumor primário de cérebro.

Com relação aos estudos que avaliaram o risco de tumor de cérebro envolvendo o consumo de água e de substâncias químicas nela contidas, pode-se inferir que a investigação de fatores isolados não propiciou uma análise mais consistente, pois é de se supor que não exista apenas uma única explicação para o aparecimento destes tumores. Poder-se-ia, inclusive, levantar a hipótese de que outros fatores presentes na própria água, como por exemplo resíduos de defensivos agrícolas ou industriais, possam estar relacionados com os níveis de nitratos e assim, também, contribuir para o desenvolvimento das neoplasias de cérebro.

Outro aspecto a ser consi derado refere-se à determinação do período etiologicamente relevante para o desenvolvimento do tumor, o qual deve levar em conta o período de latência, que no caso dos tumores de cérebro não é conhecido. Muitos autores avaliam o consumo recente, partindo da premissa de que este pode ser melhor recordado e pressupondo uma relativa estabilidade dos hábitos alimentares ao Iongo dos anos. Entretanto, é razoável supor que a dieta recente pode não representar o padrão alimentar praticado na época em que possivelmente, teriam ocorrido as fases de iniciação ou de promoção do câncer, pois os padrões de alimentação sofrem variação ao longo dos anos. Estas considerações sobre o período de referência para a obtenção de dados sobre dieta, certamente influenciam os resultados das investigações sobre dieta e tumores de cérebro; podendo ser responsáveis, em parte, pela pouca consistência dos resultados obtidos.

As afirmações de Olney et al. (1996) quanto a capacidade mutagênica do adoçante artificial 
aspartame, na indução do desenvolvimento de tumores de cérebro têm sido contestadas por outros autores. Gurney et al. (1997) consideram que a ocorrência quase simultânea do aumento das taxas de incidência de tumores de cérebro nos Estados Unidos e a introdução do aspartame na indústria de alimentos, é incoerente com o período de latência, usualmente longo, atribuído aos tumores sólidos. Esses autores sugerem que parece ser improvável que qualquer efeito carcinogênico do aspartame possa ser responsável pelas tendências observadas na incidência de tumores de cérebro.

Em resumo, a comparação dos resultados dos estudos incluídos nesta revisão é dificultada pelas diferentes metodologias empregadas. Entre estas, destacam-se: (a) as variações nos alimentos investigados em cada estudo; (b) as proporções de utilização de informantes substitutos e (c) as diferenças na sel eção dos grupos de controles. Os estudos analisados não demonstraram a robustez esperada para que se estabelecesse a relação de causalidade entre dieta e tumores de cérebro em adultos. Também não evidenciaram, em sua maioria, uma clara relação dose-resposta e a repetibilidade das observações não foi demonstrada, dados os resultados contraditórios encontrados em alguns estudos. Contudo, os resultados desses estudos são dignos de consideração, pois devese levar em conta que as exposições dietéticas são bastante disseminadas na população. De um modo geral, essas observações parecem apontar na direção de uma associação moderada entre os fatores da dieta e os tumores de cérebro, podendo-se levantar a hipótese de que determinados componentes da dieta atuem como co-carcinógenos no desenvolvimento das neoplasias cerebrais.

Há evidências de que o consumo de compostos $\mathrm{N}$-nitroso possa favorecer o desenvolvimento desses tumores, e de que o consumo de frutas e vegetais frescos provavelmente tenha papel na sua inibição. Apesar de todas as dificuldades assinaladas anteriormente, os estudos sugerem que os casos consomem mais alimentos em conserva (em geral carnes e vegetais) e ingerem menores quantidades de vegetais e de frutas frescas do que os controles. Estas associações são biologicamente plausíveis e consistentes com as observações experimentais e com outras investigações sobre câncer, em geral, e particularmente, sobre tumores de cérebro em crianças (Bunin et al., 1994; Choi, 1985; Eichholzer \& Gutzwiller, 1998; Mirvish, 1994, 1995; Preston-Martin \& Correa, 1989; Preston-Martin \& Lijinsky, 1994; Preston-Martin et al., 1996; Sarasua \& Savitz, 1994; Shephard et al., 1987; World Cancer Research Fund/ American Institute for Cancer Research, 1997).

De fato, as evidências experimentais permitem supor que alguns componentes dos alimentos podem desencadear o processo de iniciação dos tumores de cérebro, como é o caso dos compostos N-nitroso. Porém, há indicações de outros agentes carcinogênicos, cuja associação com o câncer de cérebro ainda não foi suficientemente explorada.

O papel dos alimentos e dos nutrientes como inibidores da carcinogênese de tumores cerebrais tem sido levantado em algumas investigações, mas não conhecemos a existência de efeito dose-resposta, e também é desconhecida a participação de outros componentes dos alimentos na fase de promoção destes tumores.

Alguns autores fazem referência a outros fatores decorrentes da alimentação que interferem no processo da carcinogênese. A baixa concentração de hidratos de carbono na dieta concorre para uma menor fermentação no ambiente do intestino grosso, levando a uma produção endógena dos compostos N-nitroso (Bingham, 1993). A fermentação advinda dos derivados do leite também é referida como um possível inibidor da carcinogênese (Rao et al., 1986). Um outro exemplo refere-se ao efeito do fumo e do álcool na redução dos níveis plasmáticos de betacaroteno, conhecido protetor para tumores localizados em outras partes do corpo, além dos níveis esperados pelas diferenças na ingestão do nutriente (Stryker et al., 1988), que foi sugerido por Giles et al. (1994) como tendo um possível efeito protetor para os tumores cerebrais.

Devido à instigante indicação de que a dieta exerce efeito sobre os tumores cerebrais, as investigações epidemiológicas sobre a associação da dieta com estes tumores devem considerar a análise de outros elementos provenientes da dieta, além dos compostos $\mathrm{N}$-nitroso. Desta maneira, devem procurar abordar as possíveis interações que ocorrem entre os nutrientes e as diferentes substâncias encontradas nos alimentos, e a interação entre os alimentos e outros fatores ambientais. Um outro aspecto importante, é a consideração da modificação que sofrem os componentes alimentares quando submetidos a diferentes formas de preparação, tornando relevante a inclusão de questões relacionadas com o modo de preparar os alimentos. Estes estudos deveriam, também, avaliar com maior cuidado os períodos de exposição aos fatores da dieta que devem ser privilegiados em seu desenho. A abordagem metodológica desses estudos deve ser criteriosa, de modo a prevenir a ocorrência de viéses relacio- 
nados com a seleção dos controles e minimizar os efeitos do viés de memória.

\section{Conclusões}

A revisão de 15 estudos realizados entre 1986 e 1999, avaliando a associação entre exposição aos fatores da dieta e a ocorrência de tumores de cérebro no adulto, revelou a presença de associações moderadas entre o consumo de alimentos ricos em compostos $\mathrm{N}$-nitroso e o consumo reduzido de frutas e vegetais com aquela neoplasia. O estabelecimento de relações cau- sais entre o padrão de dieta e os tumores de cérebro no adulto foi atenuado por diversos obstáculos metodológicos, tais como a heterogeneidade na seleção de controles nos estudos, a indefinição do período de latência e a utilização de informantes substitutos. Em conjunto, tais percalços parecem ter contribuído para a não reprodutibilidade de alguns resultados bem como a não observação de efeito doseresposta. Deve-se ressaltar, entretanto, que os achados acima mencionados apresentam plausibilidade biológica com os conhecimentos atuais sobre o processo de carcinogênese.

\section{Referências}

AHLBOM, A.; NAVIER, I. L.; NORELL, S.; OLIN, R. \& SPÄNNARE, B., 1986. Nonoccupational risk indicators for astrocytomas in adults. American Journal of Epidemiology, 124:334-337.

AUSTIN, H.; HILL, H. A.; FLANDERS, W. D. \& GREENBERG, R. S., 1994. Limitations in the application of case-control methodology. Epidemiologic Reviews, 16:65-76

BARRETT, J. H.; PARSLOW, R. C.; MCKINNEY, P. A.; LAW, G. R. \& FORMAN, D., 1998. Nitrate in drinking water and the incidence of gastric, esophageal, and brain cancer in Yorkshire, England. Cancer Causes \& Control, 9:153-159.

BINGHAM, S., 1993. Food components and mechanisms of interest in cancer and diet in relation to their measurement. European Journal of Clinical Nutrition, 47(Sup. 2):73-77.

BLOWERS, L.; PRESTON-M ARTIN, S. \& MACK, W. J., 1997. Dietary and other lifestyle factors of women with brain gliomas in Los Angeles County (California, USA). Cancer Causes \& Control, 8:5-12.

BOEING, H.; SCHLEHOFER, B.; BLETTNER, M. \& WAHRENDORF, J., 1993. Dietary carcinogens and the risk for glioma and meningioma in Germany. International Journal of Cancer, 53:561-565.

BUNIN, G. R.; KUIJTEN, R. R.; BOESEL, C. P.; BUCKLEY, J. D. \& MEADOWS, A. T., 1994. Maternal diet and risk of astrocytic glioma in children: A report from the Children's Cancer Group (United States and Canada). Cancer Causes \& Control, 5:177-187.

BURCH, J. D.; CRAIB, K. J. P.; CHOI, B. C. K.; MILLER, A. B.; RISCH, H. A. \& HOWE, G. R., 1987. An exploratory case-control study of brain tumors in adults. Journal of the National Cancer Institute, 78:601-609.
CANTOR, K. P.; LYNCH, C. F.; HILDESHEIM, M. E.; DOSEMECI, M.; LUBIN, J.; ALAVANJA, M. \& CRAUN, G., 1999. Drinking water source and chlorination byproducts in lowa. III. Risk of brain cancer. American Journal of Epidemiology, 150:552-560.

CHOI, B. C. K., 1985. N-nitroso compounds and human cancer. American Journal of Epidemiology, 121:737-743.

COGGON, D., 1991. Case-control and cross-sectional studies. In: Design Concepts in Nutritional Epidemiology (B. M. Margetts \& M. Nelson, ed.), pp. 354-368, New York: Oxford University Press.

DATASUS (Departamento de Informática do SUS), 1998. Sistema de Informação sobre Mortalidade 1979-1997 - Dados de Declaração de Óbito. CDROM. Brasília: Ministério da Saúde.

DUARTE, M. \& MÍDIO, A. F., 1996. Nitratos e nitritos em alimentos. Cadernos de Nutrição, 12:19-30.

EICHHOLZER, M. \& GUTZWILLER, F., 1998. Dietary nitrates, nitrites, and $\mathrm{N}$-nitroso compounds and cancer risk: A review of the epidemiologic evidence. Nutrition Reviews, 56:95-105.

FLAM M, W. G., 1997. Letter to the editor. Journal of Neuropathology and Experimental Neurology, 56:105-106.

GILES, G. G.; MCNEIL, J. J .; DONNAN, G.; WEBLEY, C.; STAPLES, M. P.; IRELAND, P. D.; HURLEY, S. F. \& SALZBERG, M., 1994. Dietary factors and the risk of glioma in adults: Results of a case-control study in Melbourne, Australia. International Journal of Cancer, 59:357-362.

GOLD, E. B., 1982. Epidemiology of brain tumors. In: Reviews in Cancer Epidemiology (A. M. Lilienfeld, ed.), v. 1, pp. 245-292, New York: Elservier/Amsterdam: North-Holland. 
GUO, W.-D.; LINET, M. S.; CHOW, W.-H.; LI, J.-Y. \& BLOT, W. J., 1994. Diet and serum markers in relation to primary brain tumor risk in China. Nutrition and Cancer, 22:143-150.

GURNEY, J. C.; POGODA, J. M.; HOLLY, E. A.; HETCH, S. S. \& PRESTON-M ARTIN, S., 1997. Aspartame consumption in relation to childhood brain tumor risk: Results from a case-control study. Journal of the National Cancer Institute, 89:1072-1074.

HOCHBERG, F.; TONIOLO, P. \& COLE, P., 1990. Nonoccupational risk indicators of glioblastoma in adults. Journal of Neuro-Oncology, 8:55-60.

HOLMBERG, L.; OHLANDER, E. M.; BYERS, T.; ZACK, M.; WOLK, A.; BRUCE, Å.; BERGSTRÖM, R.; BERGKVIST, L. \& ADAMI, H. O., 1996. A search for recall bias in a case-control study of diet and breast cancer. International Journal of Epidemiology, 259:235-244.

HOWE, G. R.; HARRISON, L. \&JAIN, M., 1986. A short diet history for assessing dietary exposure to $\mathrm{N}$ nitrosamines in epidemiologic studies. American Journal of Epidemiology, 124:595-602.

HU, J.; JOHNSON, K. C.; MAO, Y.; GUO, L.; ZHAO, X.; JIA, X.; BI, D.; HUANG, G. \& LIU, R., 1998. Risk factors for glioma in adults: A case-control study in Northeast China. Cancer Detection and Prevention, 22:100-108.

HU, J.; LA VECCHIA, C.; NEGRI, E.; CHATENOUD, L.; BOSETTI, C.; HIA, X.; LIU, R.; HUANG, G.; BI, D. \&WANG, C., 1999. Diet and brain cancer in adults: A case-control study in Northeast China. International Journal of Cancer, 81:20-23.

HURLEY, S. F.; MCNEIL, J. J.; DONNAN, G. A.; FORBES, A., SALZBERG, M. \& GILES, G. G., 1996. Tobacco smoking and alcohol consumption as risk factors for glioma: A case-control study in Melbourne, Australia. Journal of Epidemiology and Community Health, 50:442-446.

INSKIP, P. D.; LINET, M. S. \& HEINEMAN, E. F., 1995. Etiology of brain tumors in adults. Epidemiologic Reviews, 17:382-414.

JACOBS, D. R.; SLAVIN, J. \& MARQUART, L., 1995. Whole grain intake and cancer: A review of the literature. Nutrition and Cancer, 24:221-229.

KAPLAN, S.; NOVIKOV, I. \& MODAN, B., 1997. Nutritional factors in the etiology of brain tumors. American Journal of Epidemiology, 146:832-841.

KOESTNER, A., 1997. Letter to the editor. Journal of Neuropathology and Experimental Neurology, 56:107-109.

KOHLMEIER, L.; SIM ONSEN, N. \& MOTTUS, K., 1995. Dietary modifiers of carcinogenesis. Environmental Health Perspectives, 103(Sup. 8):177-184.

KOIFMAN, S., 1995. Incidência de câncer no Brasil. In: Os Muitos Brasis - Saúdee População na Década de 80 (M. C. S. Minayo, org.), pp. 143-176, São Paulo: Editora Hucitec/Rio de Janeiro: ABRASCO.

LEE, M.;WRENSCH, M \& \& MIIKE, R., 1997. Dietary and tobacco risk factors for adult onset glioma in the San Francisco Bay Area (California, USA). Cancer Causes \& Control, 8:13-24.

MARGETTS, B. M., 1991. Basic issues in designing and interpreting epidemiological research. In: Design Concepts in Nutritional Epidemiology (B. M. Margetts \& M. Nelson, ed.), pp. 13-52, New York: Oxford University Press.
MILLER, A. B.; CHOI, B. C. K.; HOWE, G. R.; BURCH J. D. \& SHERMAN, G. J., 1984. Epidemiological assessment of risk to humans from exposure to nitrosamines. IARC Scientific Publication, 57:929936.

MILLER, E. C. \& MILLER, J. A., 1986. Carcinogens and mutagens that may occur in foods. Cancer, 58: 1795-1803.

MILLS, P. K.; PRESTON-MARTIN, S.; ANNEGERS, J. F.; BEESON, W. L.; PHILLIPS, R. L. \& FRASE, G. E., 1989. Risk factors for tumors of the brain and cranial meninges in Seventh-Day Adventists. Neuroepidemiology, 8:266-275.

MIRVISH, S. S., 1986. Effects of vitamins $C$ and $E$ on $\mathrm{N}$-nitroso compound formation, carcinogenesis and cancer. Cancer, 58:1842-1850.

MIRVISH, S. S., 1994. Experimental evidence for inhibition of $\mathrm{N}$-nitroso compound formation as a factor in the negative correlation between vitamin $\mathrm{C}$ consumption and the incidence of certain cancers. Cancer Research, 54(Sup.):1948s-1951s.

MIRVISH, S. S., 1995. Role of N-nitroso compounds (NOC) and N-nitrosation in etiology of gastric, esophageal, nasopharyngeal and bladder cancer and contribution to cancer of known exposures to NOC. Cancer Letters, 93:17-48.

OLNEY, J. W.; FARBER, N. B.; SPITZNAGEL, E. \& ROBBINS, L. N., 1996. Increasing brain tumor rates: Is there a link to aspartame? Journal of Neuropathology and Experimental Neurology, 55:1115-1123.

PRESTON-MARTIN, S. \& CORREA, P., 1989. Epidemiological evidence for the role of nitroso compounds in human cancer. Cancer Surveys, 8:469473.

PRESTON-MARTIN, S. \& LIJINSKY, W., 1994. Cured meats and childhood cancer. Cancer Causes \& Control, 5:484-485.

PRESTON-MARTIN, S. \& MACK, W., 1991. Gliomas e meningiomas in men in Los Angeles County: Investigation of exposures to $\mathrm{N}$-nitroso compounds. IARC Scientific Publication, 105:197-203.

PRESTON-MARTIN, S. \& MACK, W., 1996. Neoplasms of the nervous system. In: Cancer Epidemiology and Prevention (D. Schottenfeld \& J. F. Fraumeni Jr., ed.), pp. 1231-1291, 2nd Ed. New York: Oxford University Press.

PRESTON-MARTIN, S.; MACK, W. \& HENDERSON, B. E., 1989. Risk factors for gliomas and meningiomas in males in Los Angeles County. Cancer Research, 49:6137-6143.

PRESTON-MARTIN, S.; POGODA, J. M.; MUELLER, B. A.; HOLLY, E. A.; LIJINSKY, W. \& DAVIS, R. L. 1996. Maternal consumption of cured meats and vitamins in relation to pediatric brain tumors. Cancer Epidemiology, Biomarkers and Prevention, 5:599-605.

PREUSSMAN, R., 1984. Occurrence and exposure to $\mathrm{N}$-nitroso compounds and precursors. IARC Scientific Publications, 57:3-15.

RAO, D. R.; PULUSANI, S. R. \& CHAWAN, C. B., 1986. Natural inhibitors of carcinogenesis: Fermented milk products. In: Diet, Nutrition and Cancer: A Critical Evaluation (B. S. Reddy \& L. A. Cohen, ed.), v. II, pp. 63-76, Boca Raton: CRC Press.

RYAN, P.; LEE, M. W.; NORTH, J. B. \& MCMICHAEL, A. J., 1992. Risk factors for tumors of the brain and 
meninges: Results from the Adelaide Adult Brain Study. International Journal of Cancer, 51:20-27.

SAMET, J. M., 1990. Surrogate sources of dietary information. In: Nutritional Epidemiology (W. Willett, ed.), pp. 133-142, New York: Oxford University Press.

SARASUA, S. \& SAVITZ, D., 1994. Cured and broiled meat consumption in relation to childhood cancer: Denver, Colorado (United States). Cancer, Causes and Control, 5:141-148.

SCHWARTZBAUM, J. A.; FISHER, J. L.; GOODMAN, J.; OCTAVIANO, D. \& CORNWELL, D. G., 1999. Hypotheses concerning roles of dietary energy, cured meat, and serum tocopherols in adult glioma development. Neuroepidemiology 18:156-166.

SEN, N. P., 1986. Formation and occurrence of nitrosamines in food. In: Diet, Nutrition and Cancer: A Critical Evaluation (B. S. Reddy \& L. A. Cohen, ed.), v. II, pp. 135-160, Boca Raton: CRC Press.

SHEPHARD, S. E.; SCHLATTER, C. \& LUTZ, W. K., 1987. Assessment of the risk of formation of carcinogenic $\mathrm{N}$-nitroso compounds from dietary precursors in the stomach. Food Chemical and Toxicology, 25:91-108.
STEINDORF, K.; SCHLEHOFER, B.; BECHER, H.; HORNIG, G. \& WAHRENDORF, J., 1994. Nitrate in drinking water. A case-control study on primary brain tumors with an embedded drinking water survey in Germany. International Journal of Epidemiology, 23:451-457.

STRYKER, W. S.; KAPLAN, L. A.; STEIN, E. A.; STAMPFER, M. J.; SOBER, A. \& WILLET, W. C., 1988. The relation of diet, cigarette smoking, and alcohol consumption to plasma beta-carotene and alpha-tocopherol levels. American Journal of Epidemiology, 127:283-296.

THOMAS, T. L. \& INSKIP, P. D., s.d. Brain and Other Nervous System. 5 September 1999 ঝttp:// rex. nci.nih.gov/ NCl_Pub_Interface/raterisk/risks114. html>.

WACHOLDER, S.; SILVERMAN, D. T.; MCLAUGHLIN, J. K. \& MANDEL, J. S., 1992. Selection of controls in case-control studies. II. Types of controls. American Journal of Epidemiology, 135:1029-1041.

WILLETT, W., 1998. Nutritional Epidemiology. New York: Oxford University Press.

WORLD CANCER RESEARCH FUND/AMERICAN INSTITUTE FOR CANCER RESEARCH, 1997. Food, Nutrition and the Prevention of Cancer: A Global Perspective - Summary. Washington, DC: World Cancer Research Fund/American Institute for Cancer Research. 